(C) Copyright 2013 American Meteorological Society (AMS). Permission to use figures, tables, and brief excerpts from this work in scientific and educational works is hereby granted provided that the source is acknowledged. Any use of material in this work that is determined to be "fair use" under Section 107 of the U.S. Copyright Act September 2010 or that satisfies the conditions specified in Section 108 of the U.S. Copyright Act (17 USC §108, as revised by P.L. 94-553) does not require the AMS's permission. Republication, systematic reproduction, posting in electronic form, such as on a web site or in a searchable database, or other uses of this material, except as exempted by the above statement, requires written permission or a license from the AMS. Additional details are provided in the AMS Copyright Policy, available on the AMS Web site located at (http://www.ametsoc.org/) or from the AMS at 617-227-2425 or copyright@ametsoc.org. 


\title{
Sensitivity of Lake-Effect Snowfall to Lake Ice Cover and Temperature in the Great Lakes Region
}

\author{
David M. Wright, Derek J. Posselt, and Allison L. Steiner \\ University of Michigan, Ann Arbor, Ann Arbor, Michigan
}

(Manuscript received 29 January 2012, in final form 6 September 2012)

\begin{abstract}
High-resolution Weather Research and Forecasting Model (WRF) simulations are used to explore the sensitivity of Great Lakes lake-effect snowfall (LES) to changes in lake ice cover and surface temperature. A control simulation with observed ice cover is compared with three sensitivity tests: complete ice cover, no lake ice, and warmer lake surface temperatures. The spatial pattern of unfrozen lake surfaces determines the placement of LES, and complete ice cover eliminates it. Removal of ice cover and an increase in lake temperatures result in an expansion of the LES area both along and downwind of the lake shore, as well as an increase in snowfall amount. While lake temperatures and phase determine the amount and spatial coverage of LES, the finescale distribution of LES is strongly affected by the interaction between lake surface fluxes, the large-scale flow, and the local lake shore geography and inland topography. As a consequence, the sensitivity of LES to topography and shore geometry differs for lakes with short versus long overwater fetch. These simulations indicate that coarseresolution models may be able to realistically reproduce the gross features of LES in future climates, but will miss the important local-scale interactions that determine the location and intensity of LES.
\end{abstract}

\section{Introduction}

Lake-effect snow (LES) is a common meteorological phenomenon downwind of the North American Great Lakes during late fall and winter, and is caused by the horizontal collocation of cold polar air with a relatively warm lake surface. The associated temperature contrasts between lake, land, and air lead to steep atmospheric temperature lapse rates and significant thermal energy and water vapor fluxes from the lake surface. Together, large surface-to-air temperature gradients and moisture fluxes destabilize the atmospheric boundary layer and, in some cases, initiate shallow convection. Advection of the unstable air mass downstream over and downwind of the lee shore, and the consequent frictioninduced convergence over land, can enhance the lakeinduced convection, or produce precipitation solely due to the increased mechanical shear. On average Great Lakes LES contributes between $10 \%$ and $50 \%$ of the total regional winter precipitation (Scott and Huff 1996).

Corresponding author address: Derek J. Posselt, Department of Atmospheric, Oceanic, and Space Sciences, University of Michigan, Ann Arbor, 2455 Hayward St., Ann Arbor, MI 48109-2143.

E-mail: dposselt@umich.edu
In observational studies, LES events have been classified into four morphological types: widespread coverage, shoreline bands, midlake bands, and mesoscale vortices (Kelly 1986; Schoenberger 1986; Kristovich et al. 1999, 2003; Laird 1999; Liu et al. 2004). Widespread coverage occurs over a large area, and is also commonly associated with boundary layer rolls, cellular convection, or a combination of the two. Shoreline bands occur when winds travel a short distance over the lake, and produce small linear patterns of snowfall perpendicular to the lake shore with band-to-band spacing on the order of approximately $2-5 \mathrm{~km}$. Observations and numerical simulations of these bands exhibit strong narrow updrafts, surrounded by broad regions of weaker descent (Liu et al. 2004). Midlake bands form parallel to the major axis in the middle of the lake, with the major axis being defined as the longer diameter of the elliptical lakes. These single bands can produce copious amounts of snowfall due to the long fetch over water, and are often enhanced by land-lake breezes on either side of the band, which lead to increased midlake convergence and enhanced vertical velocities (Schoenberger 1986). Mesoscale vortices are rare, and only occur under light wind conditions. Vortices form in a region of lakebreeze convergence at the center of the lake and are 
typically associated with narrow snowbands. After formation, the entire vortex is subsequently advected over land (Laird 1999).

Variations in wind speed and direction, and consequent changes in residence time of air over open water, can lead to changes in LES morphology during a single LES event. Studies using idealized lake coastlines have shown LES morphology to be dependent upon the ratio of wind speed to fetch over open water. This ratio represents the residence time of the air parcel over open water, which in turn determines the extent of destabilization and water vapor added to the air (Laird et al. 2003a,b). The wind speed to fetch ratio is limited in its predictive ability as it does not account for transition zones in which multiple types of morphology may be present simultaneously (Laird et al. 2003b). Its ability to predict morphology in observed conditions is generally limited because of complex interactions between coastlines and local and large-scale circulations (Laird and Kristovich 2004; Laird et al. 2003b).

The large-scale conditions necessary for the formation of LES have been studied extensively with a variety of models and observations, and the role of lake-atmosphere temperature gradients, wind speeds and shear, lake orientation, and bulk lake ice coverage in LES formation are now relatively well understood (Wiggin 1950; Eichenlaub 1970, 1979; Niziol 1987; Niziol et al. 1995; Ballentine et al. 1998; Kristovich and Laird 1998; Liu et al. 2006). Specifically, lake surface latent heat flux decreases linearly with increasing lake ice areal coverage, while sensible heat fluxes are relatively constant below $70 \%$ ice area fraction, rapidly decreasing with increasing ice coverage (Gerbush et al. 2008). Changes in lake ice coverage have also been shown to produce significant modifications not only to LES amount, but also precipitation morphology (Cordeira and Laird 2008). Ice thickness also modulates the water-to-air fluxes of thermal energy and water vapor, leading in some cases to relatively large fluxes even in cases with large fractional ice cover (e.g., Zulauf and Krueger 2003). As such, while relatively large ice-free surfaces are generally required for the generation of LES, a few studies have noted large fluxes in the presence of relatively high ice concentration. Specifically, cases of LES over lakes with significant (greater than $80 \%$ ) ice cover concentration over the entire lake have been observed (Laird and Kristovich 2004; Cordeira and Laird 2008). Studies conducted on decadal time scales indicate such events are rare (Notaro et al. 2013; Vavrus et al. 2013).

The magnitude of LES is to a large extent dependent on the thermal gradient between lake surface and atmosphere, and global warming-induced changes in the spatial distribution of lake ice may therefore cause changes in the characteristics of future LES events. The observed trend indicates a general decrease in lake ice coverage and thickness over the past few decades (Assel et al. 2003; Assel 2005), though there are occasionally anomalous years with larger ice extent associated with variability in the atmospheric circulation related to changes in the phase of the Arctic Oscillation and the El Niño-Southern Oscillation (ENSO; Wang et al. 2010). In addition to decreases in lake ice coverage, several recent studies suggest an increase in the frequency and intensity of LES events as lake temperatures warm. Kunkel et al. (2009) examined measurements taken during 1930-2004 at 19 National Weather Service (NWS) cooperative observing stations and found a robust upward trend in observed LES depth and liquid equivalent downwind of Lakes Superior and Michigan, while results for Lakes Erie and Ontario were mixed and dependent on the period of analysis. Burnett et al. (2003) found that the frequency of LES events increased over all lakes during the 1990s and associated this increase with a rise in Great Lakes average lake surface temperatures (LSTs) of approximately $1^{\circ} \mathrm{C}$ from $1995-2000$. The frequency and intensity of cold-air outbreaks did not change during this time period (Walsh et al. 2001), even under conditions of strong surface warming. Studies using various Intergovernmental Panel on Climate Change (IPCC) emissions scenarios project increases of $2.5^{\circ}-$ $7.0^{\circ} \mathrm{C}$ in LST over the Great Lakes by the year 2100 (Trumpickas et al. 2009), but it is unclear if changes in temperature will be accompanied by increases in the frequency or intensity of LES. Kunkel et al. (2002) examined output from two global climate model (GCM) simulations and found that intense LES events (those that produce greater than $35 \mathrm{~cm}$ of snow) decrease in frequency in the latter part of the twenty-first century, likely due to a decrease in the projected number of coldair outbreaks (Vavrus et al. 2006).

While the literature indicates a general increase in the intensity of LES in a warming climate, determination of the local-scale distribution of LES is complicated by the interaction between the large-scale flow and the lake shore geography and topography. As such, the mechanistic details of how the distribution and intensity of LES might change in a warming climate are not yet clear. Studies of the morphology of LES (e.g., Kristovich et al. 2003) reveal a high degree of event-to-event diversity in finescale precipitation structure, requiring models that account for the response of mesoscale dynamics and cloud system properties to changes in the large-scale environment. The goal of this study is to examine the mesoscale and cloud-scale changes to 
precipitation structure overlake and downwind that arise from changes to Great Lakes ice coverage and lake temperature consistent with future climate conditions. Specifically, we use a set of control and sensitivity simulations to determine whether changes in LES in a warming climate can be described simply as a response to changes in the overlake fluxes, or whether these changes are modulated by interaction with the localscale topography and shore geometry. To understand local- and regional-scale interactions at the process level, we focus on a specific event that occurred during 14-17 January 2009, and employ high-resolution Weather Research and Forecasting Model (WRF) simulations with differing lake ice coverage and LSTs consistent with conditions projected for the latter half of the twenty-first century. We first examine the regional-scale snowfall response and then perform a more detailed analysis of the finescale precipitation structures.

The remainder of this paper is organized as follows. Section 2 contains an overview of the WRF configuration and physical parameterizations, a description of the modifications used to test the sensitivity of the event to lake conditions, and an overview of our selected case. Section 3 reports the results of each experiment, and a summary and conclusions are presented in section 4.

\section{Model setup and description of the January 2009 case}

\section{a. Model configuration}

The Advanced Research Weather Research and Forecasting Model (WRF-ARW), version 3.2.1, is utilized to simulate LES over the Great Lakes region. The model is run on two nested domains, including 1) a $3-\mathrm{km}$ horizontal grid spacing and 35 terrain-following vertical levels on the outer domain and 2) a 1-km grid spacing and 69 vertical levels on the inner nest (Fig. 1). One-way nesting is used to transfer information between outer and inner nests. Initial and lateral boundary conditions for the 3-km nest are obtained from the North American Regional Reanalysis (NARR) dataset, and lateral boundary conditions are updated every $3 \mathrm{~h}$. Each simulation is run for a total of $60 \mathrm{~h}$ starting at $1200 \mathrm{UTC}$ 14 January and ending at 0000 UTC 17 January 2009. LES initiation occurred at approximately 0000 UTC 15 January, and the model was started $12 \mathrm{~h}$ previous to allow sufficient time for initialization and spin up.

All simulations employ the Goddard microphysics and Mellor-Yamada-Janic planetary boundary layer schemes, as these parameterizations have demonstrated

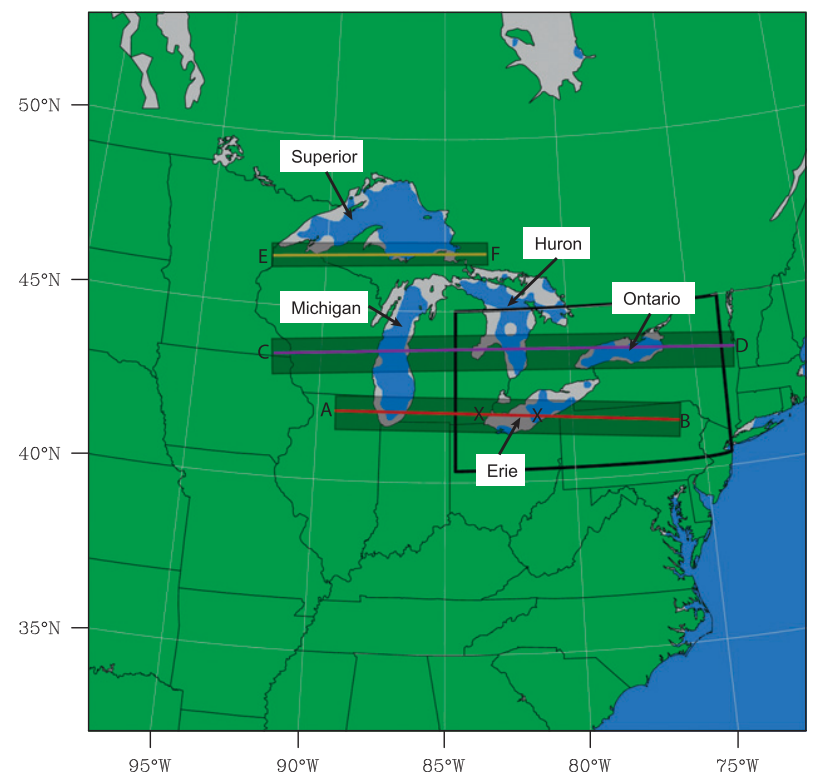

FIG. 1. Geographic extent of the WRF domain. Light gray shading over the lakes depicts the lake ice coverage as initialized by the model. Dark gray shading delineates the area average for precipitation transects analyzed in section $3 \mathrm{a}$, while the $\times$ s mark the locations of the soundings plotted in Fig. 8. The location of the inner (1-km grid spacing) nest is depicted in the black box.

success in modeling LES events in previous studies (Shi et al. 2010). See Table 1 for the complete suite of physics schemes used. The fine horizontal grid spacing used in our simulations obviated the need for a deep convective parameterization. While the horizontal grid spacing used on both model domains is too coarse to resolve individual shallow convective elements, as of yet there is no shallow convective parameterization appropriate for the simulation of LES. If, in general, a minimum of foursix model grid points are required to resolve a physical structure (Grasso 2000; Durran 2000), simulation of individual $1 \mathrm{~km}$ in width LES bands would require horizontal grid spacing less than $250 \mathrm{~m}$. Computational limitations restricted the simulations used in this study to a horizontal grid spacing of $1 \mathrm{~km}$ in length and larger. Comparison between simulated snowbands and those observed indicates the grid spacing was sufficient to reproduce the observed mesoscale cloud structure and precipitation distribution.

The Noah land surface model is used to simulate subsurface temperature and soil moisture. LST and sea surface temperatures (SST) are initialized using satellitederived surface skin temperature in the NARR dataset, with lake ice grid cells defined as any inland water points with LST at or below $271 \mathrm{~K}$. Lake ice grid cells (Fig. 1) are treated as bare land, with the subsurface treated as saturated frozen soil. Temperatures of ice grid points 
TABLE 1. Parameterization schemes used in the setup of WRF.
Microphysics

Planetary boundary layer

Land surface model

Shortwave radiation physics

Longwave radiation physics

Cumulus scheme

Surface layer physics
Goddard microphysics scheme

Mellor-Yamada-Janjic scheme

Noah land surface model

Dudhia scheme

Rapid Radiative Transfer Model

None

Eta similarity decrease linearly to $270 \mathrm{~K}$ at a depth of $1.5 \mathrm{~m}$ below the surface, while water points with temperatures greater than $271 \mathrm{~K}$ are isothermal through this depth.

In addition to the control simulation (hereafter CTRL), three test cases are used to explore the impacts of ice coverage and lake surface temperature on the formation of lake-effect precipitation. These employ the following surface boundary conditions: 1) all lakes are assumed to be completely ice covered (ALLICE) by setting initial skin temperatures over lakes to $265 \mathrm{~K}$ (the average NARR skin temperature for all ice covered lake points), 2) all lakes are assumed to be ice free (NOICE) by setting any lake point temperatures below 273.15 to $273.2 \mathrm{~K}$, and 3) all lakes are assumed to be ice free and with a surface temperature uniformly $3 \mathrm{~K}$ greater than the ice-free case (LST3K). Changes to the surface boundary conditions are only applied to continental water points, and points over the Atlantic Ocean are left unmodified. Our focus is restricted to the areas immediately surrounding the Great Lakes. With the exception of changes in the lake ice, all other initialization remains the same and the simulations are otherwise identical with respect to length of simulation, resolution, parameterizations, and boundary conditions.

\section{b. Overview of the January 2009 case}

Here we provide a brief overview of the synoptic-scale conditions observed during the January 2009 cold-air outbreak case using NARR temperature, geopotential height, and wind data at $850 \mathrm{hPa}$. At 1200 UTC 15 January 2009, a high-amplitude ridge-trough system was located over North America with a trough that stretched from Ontario south along the Atlantic coastline (Fig. 2a). Temperatures over the Great Lakes region were uniformly lower than $-20^{\circ} \mathrm{C}$, and winds over the lakes were oriented primarily from northwest to southeast at this time. The surface cyclone (indicated by the "L" in Figs. 2a,b) was located over the Atlantic Ocean just east of the mid-Atlantic states. By 0000 UTC 16 January, the surface cyclone had moved farther offshore and winds over the Great Lakes had acquired a more westerly component. At 1200 UTC 16 January, winds over the lakes were oriented primarily from west to east, and while $850-\mathrm{hPa}$ temperatures had increased over the
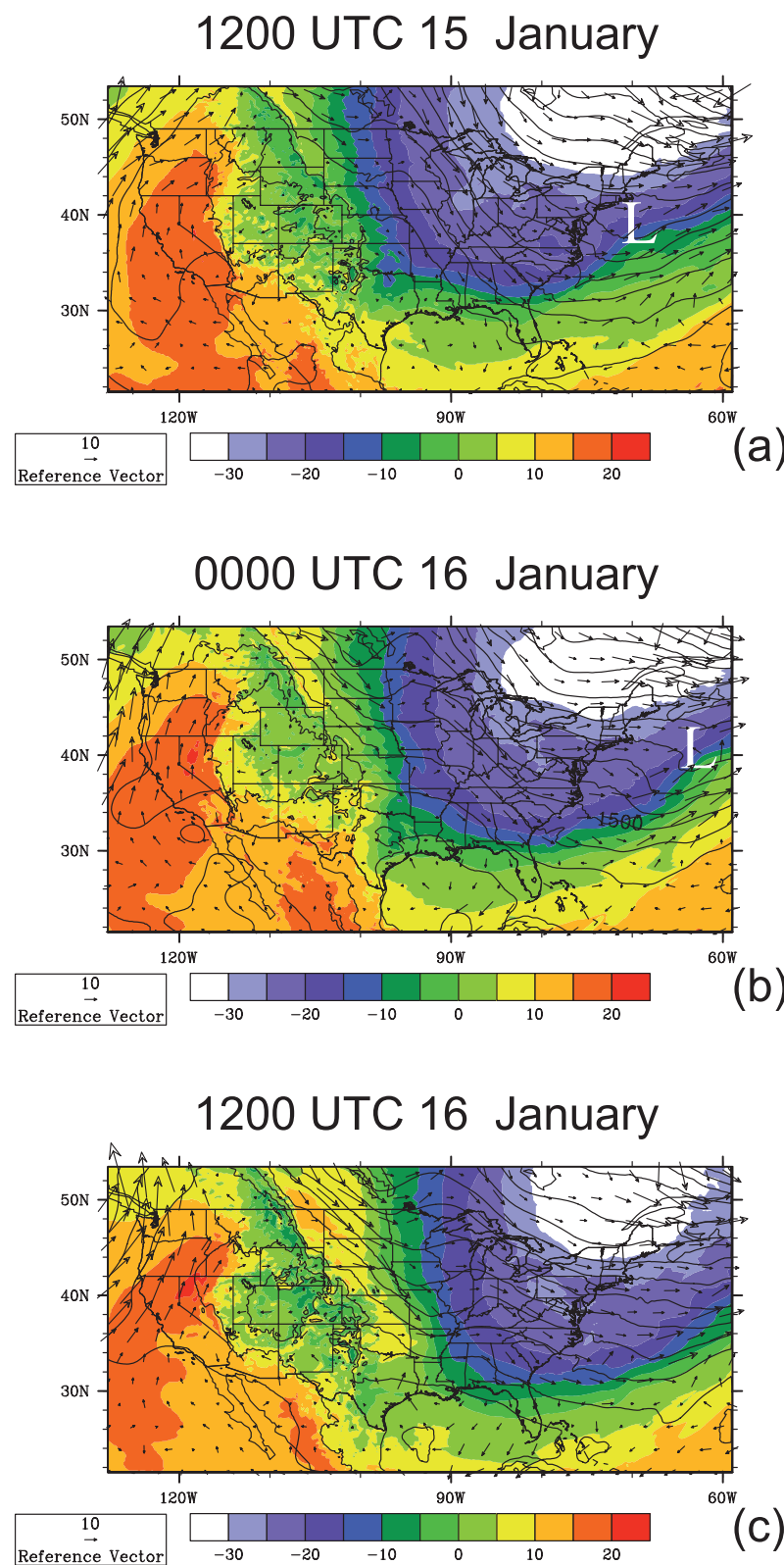

FIG. 2. 850 -hPa geopotential height $(\mathrm{m})$ and temperature $\left({ }^{\circ} \mathrm{C}\right)$ from the NARR dataset at (a) 1200 UTC $15 \mathrm{Jan}$, (b) 0000 UTC $16 \mathrm{Jan}$, and (c) 1200 UTC 16 Jan. The position of the surface cyclone is indicated in the white " $\mathrm{L}$ " in (a) and (b).

preceding $12 \mathrm{~h}$, the air over the Great Lakes region remained colder than $-15^{\circ} \mathrm{C}$. With open-water temperature $\geq 0^{\circ} \mathrm{C}$, all lakes satisfy the Holroyd (1971) criterion of $13^{\circ} \mathrm{C}$ difference between $850 \mathrm{mb}$ and LST for the formation of LES.

To evaluate the control simulation of LES for this event, we compare simulated versus observed composite radar reflectivity, as liquid equivalent precipitation is difficult to measure accurately over broad spatial scales 


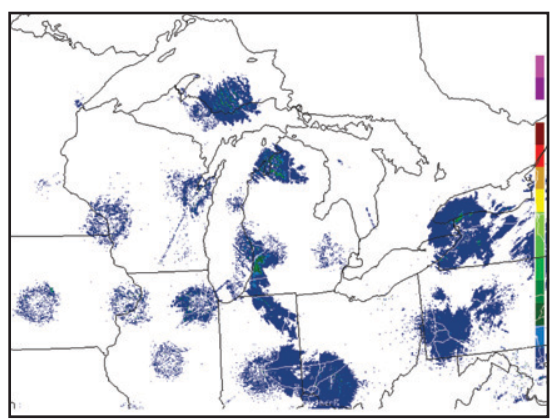

(a)

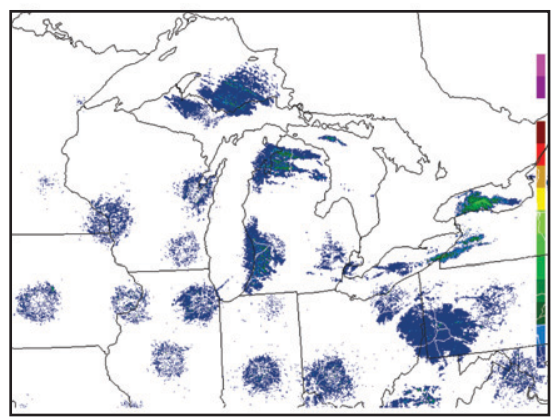

(c)
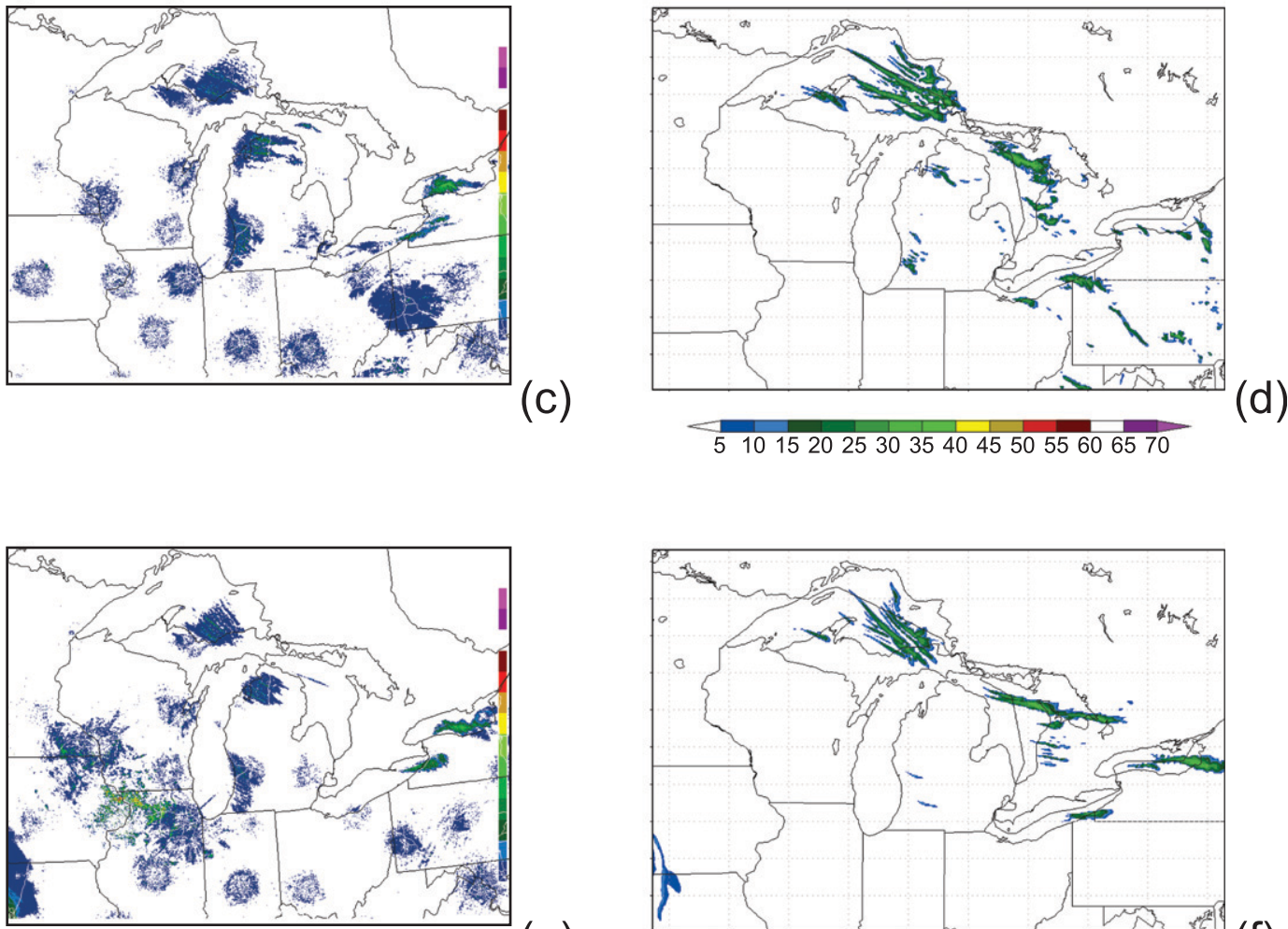

(e)

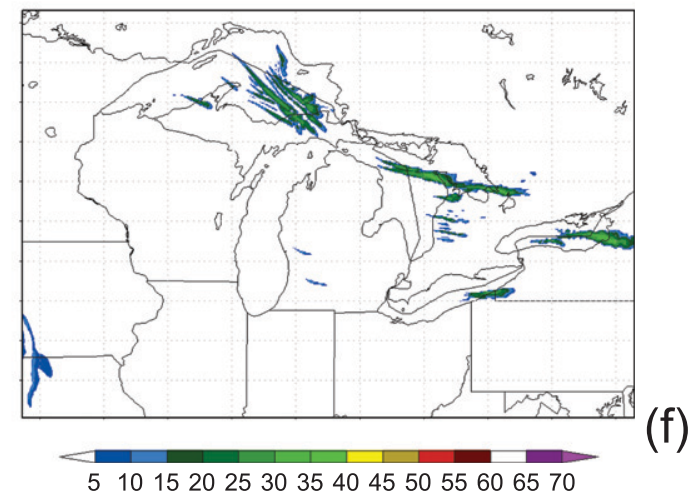

FIG. 3. (a),(c),(e) Observed and (b),(d),(f) WRF-simulated composite radar reflectivity (dBZ) from (a),(b) 1200 UTC 15 Jan 2009; (c),(d) 0000 UTC 16 Jan 2009; and (e),(f) 1200 UTC 16 Jan 2009.

with either in situ or radar observations. Simulated reflectivity was generated using the Advanced Research WRF postprocessing package (ARWpost), which computes equivalent reflectivity factor from the mass and particle size distribution of all precipitating hydrometeors (rain, snow, and graupel). Brightband effects are simulated by scaling the equivalent reflectivity factor of snow and graupel at temperatures greater than freezing. The combined reflectivity factors from all precipitating

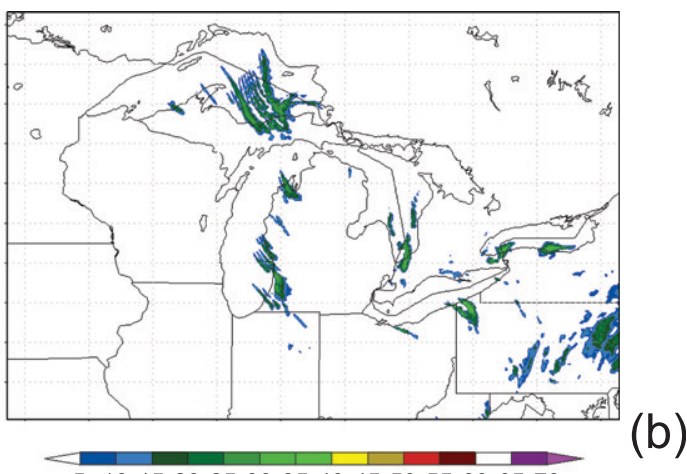

d)

hydrometeors are then summed and converted to reflectivity in $\mathrm{dBZ}$. Although simulated radar reflectivity is not an exact analog to the precipitation rate at the surface, it does facilitate comparison of the simulated and observed precipitation spatial scale and cloud hydrometeor content. At 1200 UTC 15 January (Fig. 3a), the model produces lake-effect snowfall over and downwind of each of the Great Lakes. Comparison with the observed radar reflectivity (Fig. 3b) indicates the 
model is producing precipitation in close proximity to most of the observed locations, with particularly good agreement downwind of Lake Michigan. Note that there are modeled LES bands over Lake Huron and downwind of Lake Erie that are not seen in the observed radar imagery. The bands over Lake Huron appear in geostationary satellite imagery (not shown). They do not appear in the current images due to NWS Next Generation Weather Radar (NEXRAD) radar coverage not extending past Lake Huron, and radar overshooting the tops of the shallow convection, although we note that these bands are observed in Canadian-based radar sites (not shown). The modeled bands downwind of Lake Erie that are not observed in the radar observations form in close proximity to the region of open water over the lake (see ice extent depicted in Fig. 1), and it is possible that local-scale convergence features around the ice edge may be enhancing the precipitation in the model at this time. The model produces precipitation features over and downwind of the lakes that are very consistent with those observed at 0000 and 1200 UTC 16 January (Figs. 3b-d and 3e,f, respectively), though the midlake band over Lake Ontario is slower to develop in the model than in reality. The broad region containing large reflectivity values over southern Wisconsin and northern Illinois at 1200 UTC 16 January (Fig. 3e) is not produced by the model (Fig. 3f). Surface observing stations and satellite images over this region (not shown) report uniformly clear skies at this time. The relatively large observed reflectivities may be caused by downward refraction of the radar beam (and subsequent intersection with the surface) in the presence of extremely cold air in this region (approximately $-30^{\circ} \mathrm{C}$ at this time).

As mentioned in the introduction, LES differs in morphology according to the details of the large-scale wind flow, fetch, and lake surface-air temperature difference. Examination of the simulated reflectivity output from the model reveals evidence of each of the observed types of LES with the exception of mesoscale vortices, which are prevented by the persistence of strong winds over the lakes for the duration of the event. Shoreline bands are evident south of Lake Ontario at 1200 UTC 15 January and south of Lake Erie at 0000 and 1200 UTC 16 January. Midlake bands can be seen over Lakes Superior and Huron at 0000 and 1200 UTC 16 January and over Lake Ontario at 1200 UTC 16 January.

Comparison with the ice concentration analysis from the National Ice Center over the Great Lakes shows a close agreement in the location of ice between observations and the WRF (not shown). The most notable error occurs over central Lake Huron, where WRF includes an isolated region of ice that is not seen in the satellite observations. All other lakes show reasonable agreement with observations, with minor errors in extent of ice coverage over Lakes Erie, Ontario, and Superior. Note that ice location and thickness is not updated during our WRF simulations. Ice concentration is observed to change during 15-17 January, in particular associated with formation of thin new ice over Lake Erie and south-central Lake Superior. However, the maximum ice depth observed during the simulated time period is $30-70 \mathrm{~cm}$ over small portions of Lake Erie's western basin, Green Bay in northwest Lake Michigan, off the coast of Manitoulin Island in northeastern Lake Huron, Saginaw Bay in Lake Huron, and off the coast of Thunder Bay, Ontario, in the northern part of Lake Superior. Other ice-covered areas range in thickness from new ice to $10-30 \mathrm{~cm}$. Since the changes in ice cover are small, we expect the discrepancies due to the lack of an ice cover update in our model to be negligible.

\section{Results from lake surface sensitivity tests}

\section{a. Changes in regional precipitation distribution}

As mentioned in the introduction, we begin with an analysis of changes in the regional distribution of LES and then proceed to a detailed examination of cloud and precipitation structure. We base our analysis on the area downwind of the Great Lakes with output from the larger region encompassed by the 3-km nest, and utilize the higher-resolution 1-km nest to explore the interaction between LES, topography, and shoreline geography in section 3c. Figure 4 displays the cumulative liquid equivalent precipitation in the CTRL (Fig. 4a), ALLICE (Fig. 4b), NOICE (Fig. 4c), and LST3K (Fig. 4d) cases, along with difference plots (Figs. $4 \mathrm{e}-\mathrm{g}$ ) for the time period spanning 0000 UTC 15 January-0000 UTC 17 January 2009. Precipitation in CTRL (Fig. 4a) is due both to the frontal and synoptic-scale forcing for vertical motion associated with the passage of the midlatitude cyclone as well as the effect of the lakes on the formation of LES. Each of the Great Lakes is producing lake-effect precipitation both over and downwind of the lake, with precipitation maxima located primarily along the downwind (southern and eastern) shores. Local precipitation minima along the northwest shore of Lake Superior, as well as the southwestern and southeastern shore of Lake Erie are associated with ice cover in these regions.

Comparison of the results for CTRL (Fig. 4a) and ALLICE (Fig. 4b), as well as the difference plot in Fig. $4 \mathrm{e}$, illustrates the influence of lake ice on the generation of lake-effect precipitation. Less than $3 \mathrm{~mm}$ of total precipitation is produced in the ALLICE simulation over or downwind of the lakes (Fig. 4b). The reduction 

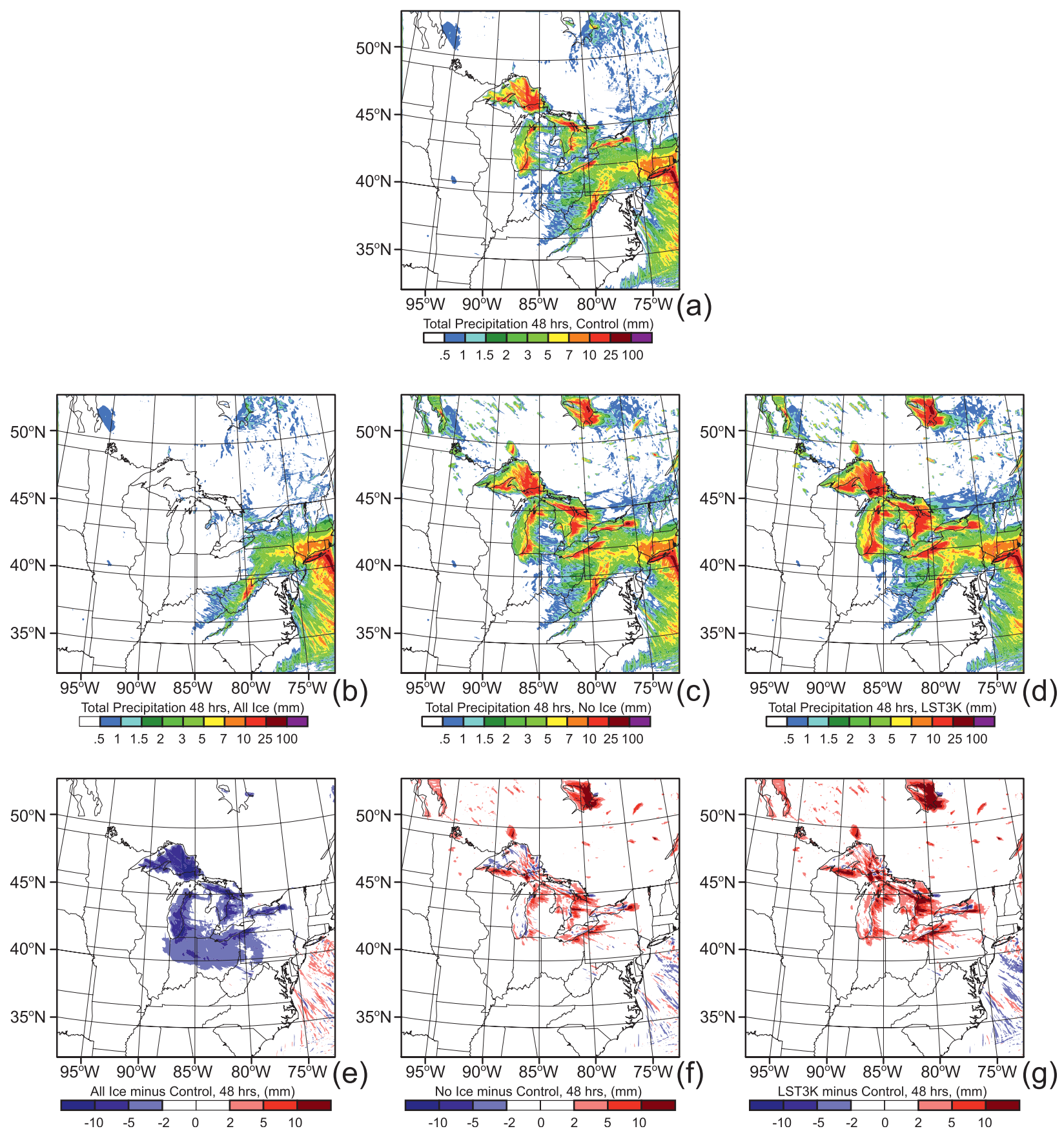

FIG. 4. 48-h (0000 UTC 15 Jan-0000 UTC 17 Jan) accumulated precipitation (mm) from (a) CTRL, (b) ALLICE, (c) NOICE, and (d) LST3K. Difference plots (taken with respect to CTRL) are depicted in the third row for (e) ALLICE - CTRL, (f) NOICE - CTRL, and (g) LST3K - CTRL.

in precipitation is most notable in the western portion of Michigan's lower peninsula, throughout Michigan's upper peninsula, and along the southern and western shores of Lake Erie. In the absence of LES, all accumulated precipitation in the ALLICE case is associated with the passage of the midlatitude cyclone. The small amount of accumulated precipitation over southern Michigan and northwestern Ontario is likely due to convective instability in the cold air to the northwest of the surface cyclone. The simulation of complete ice coverage not only removes the lake-effect precipitation over and immediately downwind of the lakes, it also has 
TABLE 2. Number of grid cells in the Great Lakes region reporting $2 \mathrm{~mm}$ or more and $10 \mathrm{~mm}$ or more of precipitation.

\begin{tabular}{|c|c|c|c|}
\hline & CTRL & NOICE & LST3K \\
\hline \multicolumn{4}{|c|}{48 -h accumulation greater than or equal to $2 \mathrm{~mm}$} \\
\hline No. of grid cells & 45060 & 57455 & 62935 \\
\hline$\%$ change from CTRL & & $27.5 \%$ & $39.7 \%$ \\
\hline$\%$ change from NOICE & & & $9.5 \%$ \\
\hline \multicolumn{4}{|c|}{$48-\mathrm{h}$ accumulation greater than or equal to $10 \mathrm{~mm}$} \\
\hline No. of grid cells & 4133 & 7954 & 12986 \\
\hline$\%$ change from CTRL & & $92.5 \%$ & $214.2 \%$ \\
\hline$\%$ change from NOICE & & & $63.3 \%$ \\
\hline
\end{tabular}

the effect of removing all accumulated precipitation over southern Michigan and most of Indiana and Ohio (Fig. 4e). The lakes are too far removed to directly contribute to the formation of precipitation in these regions, but the absence of water vapor from overlake evaporation in the ice-covered case leads to a drier atmosphere, and hence to the suppression of synoptically forced precipitation in these regions.

The precipitation distribution in NOICE (Fig. 4c) is similar to the pattern seen in CTRL (Fig. 4a), with the most intense areas of precipitation located along the southern shores of Lakes Superior and Erie, the east coast of Lake Ontario, and the eastern shores of Lakes Michigan and Huron. Though the patterns of precipitation are similar between CTRL and NOICE, areas receiving relatively small $(\geq 2 \mathrm{~mm})$ and large $(\geq 10 \mathrm{~mm})$ amounts of precipitation increase $28 \%$ and $93 \%$, respectively, over the CTRL case (Table 2). The NOICE CTRL difference plot (Fig. 4f) reveals a general increase in precipitation downwind of each of the lakes. Decreases in precipitation over each of the lakes is primarily due to a shift in the position of the midlake band(s) caused by the removal of ice, while decreases farther to the south and east of Lakes Michigan, Erie, and Ontario are associated with small shifts in the position of downwind snowbands.

When LST is increased by $3 \mathrm{~K}$ over the no ice case (Fig. 4d), the spatial structure of the accumulated precipitation changes little compared with NOICE (Fig. 4c); however, the total area that encompasses all accumulated snowfall increases. In addition, the overall intensity of precipitation increases substantially, with areas that experience relatively large precipitation $(\geq 10 \mathrm{~mm})$ increasing by $63.3 \%$ over the no ice case (Table 2; Fig. 5 ). The plot of the difference between LST3K and CTRL (Fig. 4f) indicates precipitation is not only more intense along the downwind lake shores, but also exhibits deeper inland propagation. A comparison of our results to the climatological precipitation in the Great Lakes region (e.g., Scott and Huff 1996) reveals the accumulated precipitation in our simulations of this single case is

\section{Hour Accumulated Precipitation, $\geq 2 \mathrm{~mm}$}
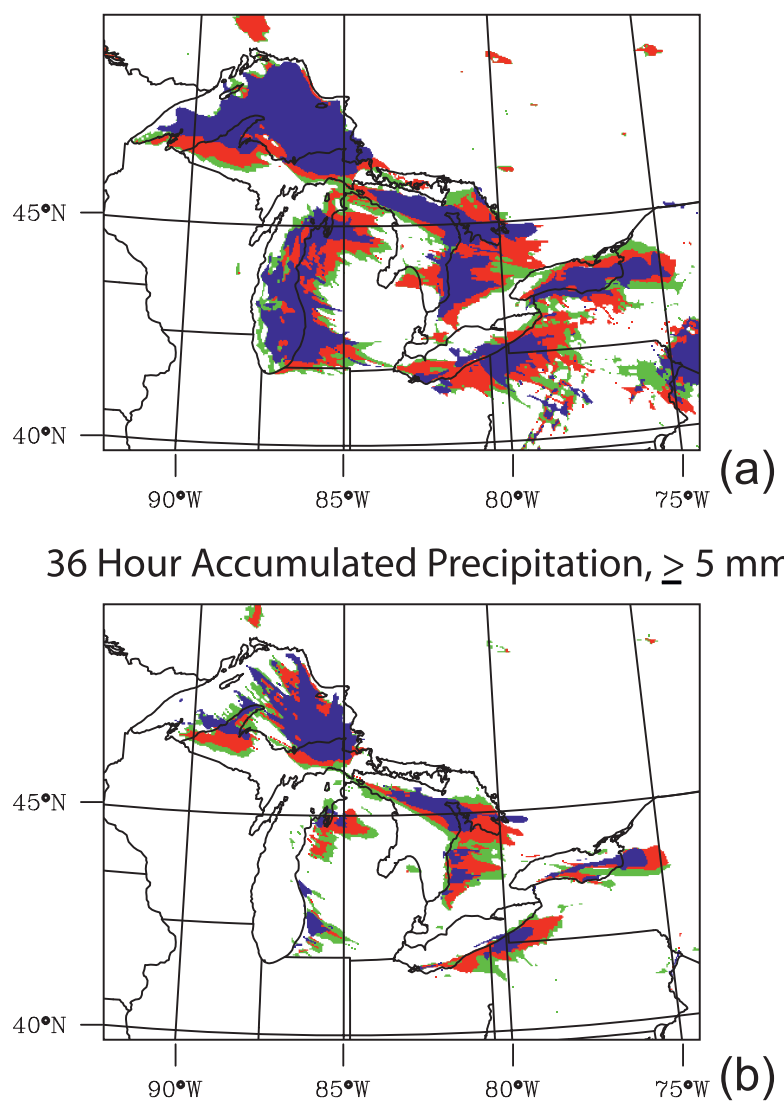

36 Hour Accumulated Precipitation, $\geq 10 \mathrm{~mm}$

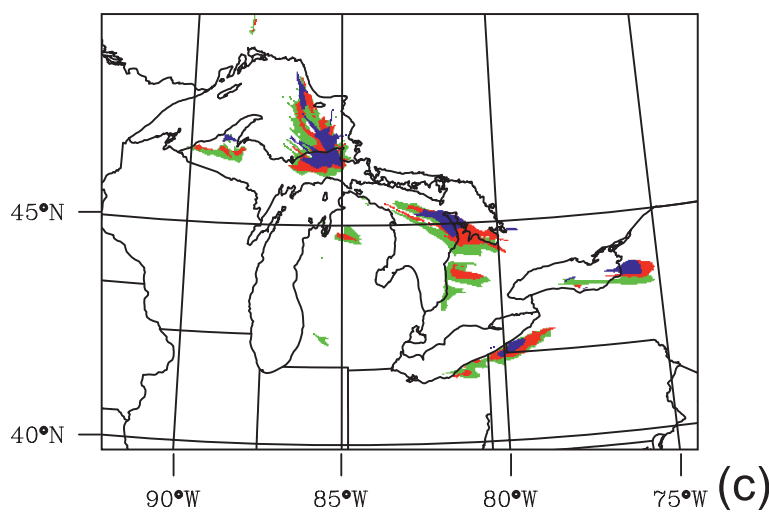

FIG. 5. Mask enclosing regions of 36-h accumulated precipitation greater than or equal to (a) 2, (b) 5, and (c) $10 \mathrm{~mm}$. In each plot, the blue area encloses precipitation from CTRL, red from NOICE, and green from LST3K.

equivalent to approximately $3 \%-7 \%, 4 \%-9 \%$, and $5 \%-$ $17 \%$ of the total average wintertime precipitation in the CTRL, NOICE, and LST3K cases, respectively.

The change in LES coverage between CTRL, NOICE, and LST3K is evident when masking the 36 - $\mathrm{h}$ precipitation amounts $\geq 2$ (Fig. 5a), $\geq 5$ (Fig. 5b), and $\geq 10 \mathrm{~mm}$ 

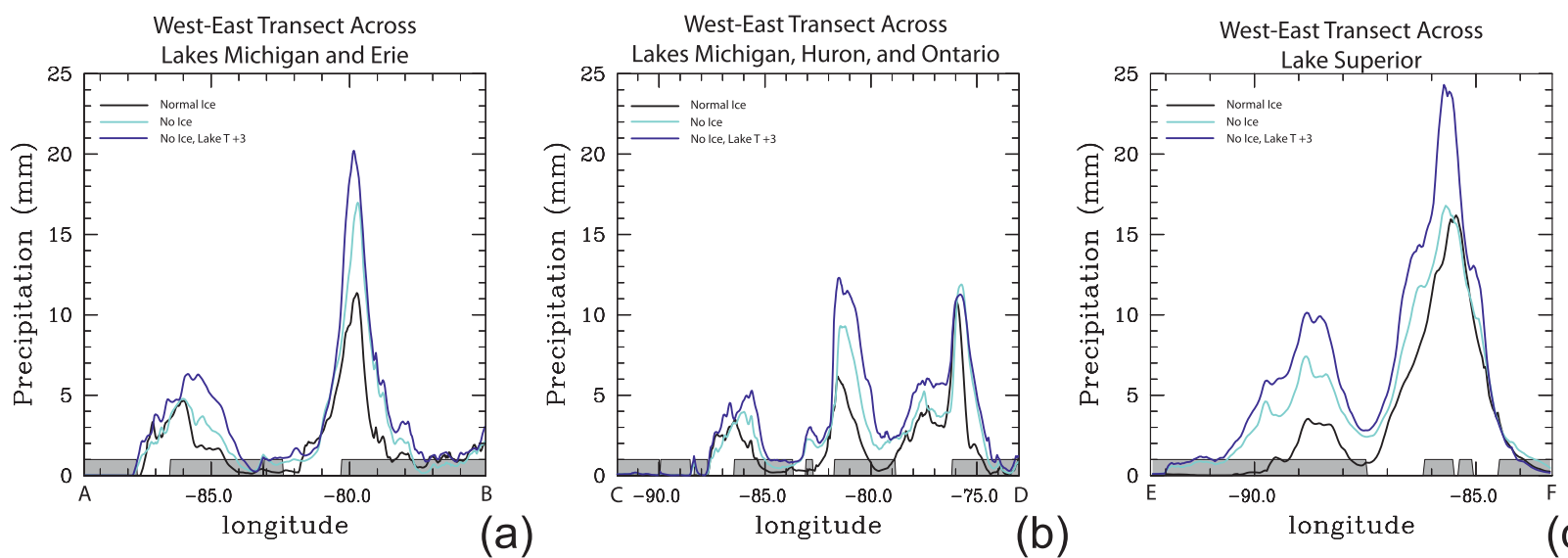

(c)

FIG. 6. Precipitation averaged along the transects shown in Fig. 1. Mean liquid equivalent precipitation ( $\mathrm{mm}$ ) is depicted for the control (black line), no-ice (cyan line), and +3 -K LST (blue line) cases. The gray shading at the bottom shows the land area with white areas depicting the locations of (a) (left) Lake Michigan and (right) Lake Erie in transect A-B, (b) Lakes Michigan, Huron, and Ontario from left to right in transect C-D, and (c) Lake Superior in transect E-F.

(Fig. 5c). The 36-h time period ending at 0000 UTC 17 January is chosen to isolate the signal of lake-effect snow and minimize the contribution from precipitation produced by the surface cyclone to the east. For each threshold value, the area of LES expands with a decrease in ice fraction and increase in LST. The largest increases in area covered by LES at each threshold occur when all ice is removed from the lakes with more modest areal increases in LES with an increase in LST. The expansion of LES with a transition to NOICE and LST3K does not solely occur in the downwind direction, but expansion is also evident in the upstream direction, and perpendicular to the flow.

We further investigate changes in the intensity and inland propagation of precipitation by examining precipitation transects across several of the lakes, where precipitation is averaged perpendicular to the transect over the gray shaded areas in Fig. 1. For the transect across Lakes Michigan and Erie (Fig. 6a), the removal of ice cover and increase in LST triggers little change in precipitation over Lake Michigan, while precipitation downwind of the lake increases by approximately $50 \%$. In contrast, the removal of ice increases precipitation at the lake shore both over and downwind of Lake Erie. The location of the precipitation maximum is unchanged for both lakes in all three simulations but LST3K, for which the maximum in precipitation moves downwind of Lake Michigan. In the transect across Lakes Michigan, Huron, and Ontario (Fig. 6b), removal of lake ice and increase in LST result in an approximately $30 \%$ increase in LES downwind of Lakes Michigan and Huron. The removal of ice over Saginaw Bay (approximately $83.5^{\circ} \mathrm{W}$; see Fig. 1 for a map of ice cover) also causes an increase in LES over the western portion of Lake Huron and Michigan's northeast lower peninsula in the NOICE simulation. LES magnitude over Lake Ontario increases by less than $10 \%$ with the removal of ice, but increases by approximately $500 \%$ downwind over land in areas originally experiencing minimal precipitation. In contrast to the southern transect, the location of the precipitation maximum shifts downstream of Lakes Michigan and Ontario, while remaining nearly stationary over Lake Huron.

In the northern west-east transect across the upper peninsula of Michigan and portions of Lake Superior (Fig. 6c), when ice is removed (NOICE) and LSTs increased (LST3K), precipitation amounts increase downwind of the lake from $40 \%$ over the eastern portion to $150 \%$ over the western edge. This variability in the increase of precipitation is mainly due to the spatial pattern of ice coverage, as well as the morphology of the shoreline (Fig. 1). The largest fractional ice coverage in CTRL is located in the western basin of Lake Superior, and removal of ice lengthens the open-water fetch in this region. Increased fetch, and consequent increases in latent and sensible heat fluxes, lead to increases in the areal extent of precipitation over land (e.g., west of $90^{\circ}$ ), but minimal change in location and magnitude of the precipitation maximum downwind of the lake (near $85^{\circ} \mathrm{W}$ ). When LSTs are increased, the location of the precipitation maximum changes little, but there is a $40 \%$ increase in liquid equivalent snowfall. In this case, there is little to no increase in open-water fetch. Instead, increases in snowfall between NOICE and LST3K are due to a surface-warming-induced increase in the magnitude of surface sensible and latent heat fluxes (Fig. 2).

The precipitation mask (Fig. 5) and transects (Figs. $6 a-c)$ show an increase in the intensity of the precipitation 


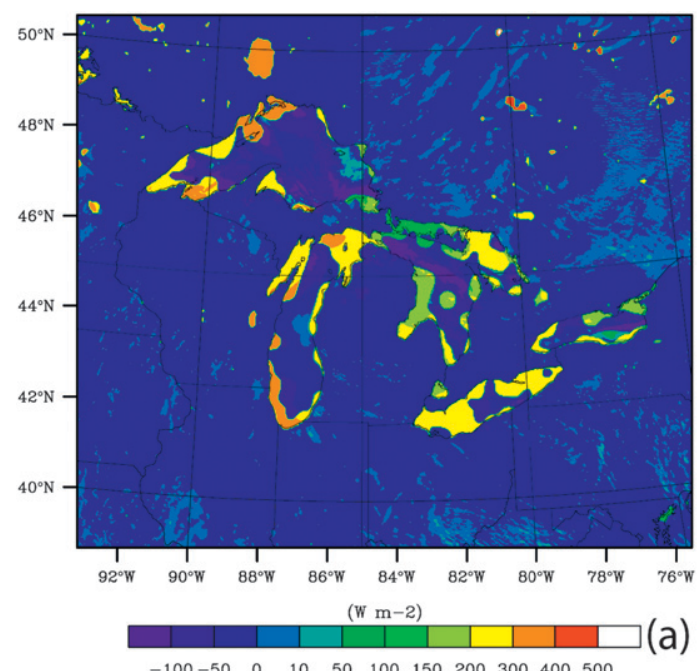

$\begin{array}{llllllllll}-100-50 & 0 & 10 & 50 & 100 & 150 & 200 & 300 & 400 & 500\end{array}$

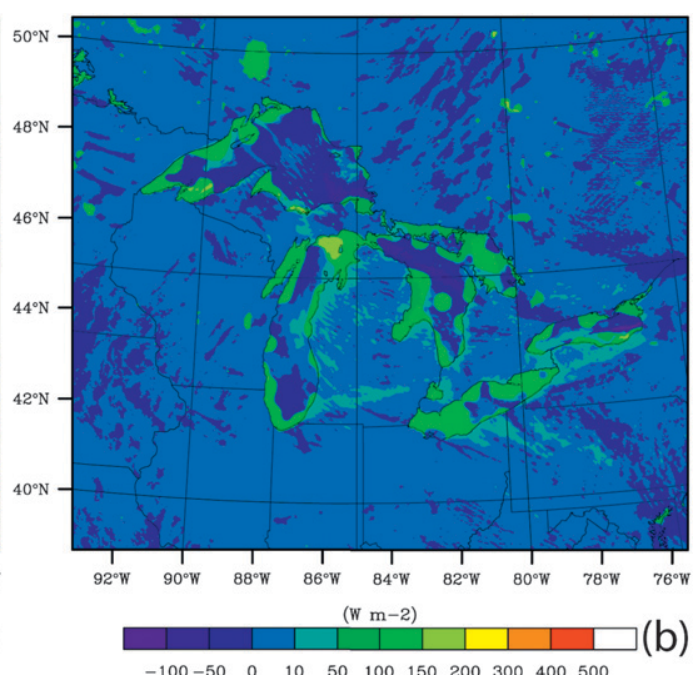

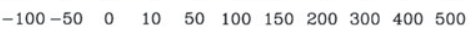

FIG. 7. NOICE - CTRL percent change in the daytime mean (1600-1900 local time) surface (a) sensible and (b) latent heat flux.

downwind of each of the lakes in NOICE and LST3K. The location of the precipitation maximum also shifts inland of Lake Michigan in both the NOICE and LST3K experiments, whereas the position of peak precipitation downwind of all of the other lakes shifts very little (typically less than $10 \mathrm{~km}$ ). Over most lakes, the increase in precipitation associated with removal of lake ice is of the same order of magnitude as the additional increase due to lake surface warming. The exceptions are those regions more than $50 \mathrm{~km}$ downwind of Lakes Erie and Ontario, which do not experience an increase in precipitation with increases in LST (Figs. 6a,b). This distinguishes the precipitation response between eastwest-oriented lakes and north-south-oriented lakes, with increases in LST causing an increase in precipitation upwind for east-west lakes (Erie and Ontario) and downwind for north-south lakes (Michigan and Huron). This is consistent with the known contribution of north-south-oriented lakes to increased precipitation downwind of downstream lakes (so-called lake-to-lake snowfall events; e.g., Rodriguez et al. 2007).

Both the precipitation mask plots (Fig. 5) and transects (Fig. 6) suggest that removal of ice (and consequent increases in overwater fetch) expands the total area affected by LES more than increases in LST. Warming of the lake surface leads to a modest expansion in LES area, but serves primarily to increase the area over which heavy precipitation (accumulated liquid amounts $\geq 10 \mathrm{~mm}$ ) falls. This is because the ice cover in CTRL is not uniformly distributed over the lakes; when ice is removed, the lake surface fluxes increase, but not in a spatially uniform fashion. As such, there are regions downstream of the lakes in CTRL that do not exhibit any lake-effect snowfall. When ice is removed and overwater fetch increases, the area of influence of lakeeffect precipitation expands. Increases in precipitation amount and intensity downwind of the lakes are likely due to larger total latent and sensible heat fluxes from the lake surface, which in turn lead to increased destabilization of the lower atmosphere and to stronger convective updrafts. These mechanisms are discussed in section $3 b$.

\section{b. Mechanisms}

Both sensible and latent heat fluxes increase over each of the lakes with the removal of ice and increase in LST, and the largest changes occur over areas previously covered by ice (Figs. 7a,b, respectively). Daytime sensible heat fluxes increase $100-400 \mathrm{~W} \mathrm{~m}^{-2}$ over areas previously covered by ice, with the largest increases occurring over western Lake Michigan and northern Lake Superior. Removal of lake ice increases the daytime latent heat fluxes $100-200 \mathrm{~W} \mathrm{~m}^{-2}$. An increase in LST leads to a smaller increase in fluxes from the lake surface compared with removal of lake ice; surface fluxes in LST3K are at most $10 \mathrm{~W} \mathrm{~m}^{-2}$ larger than those in the NOICE case (not shown). While the magnitude of the increases due to warming LST is smaller, they occur over a far greater area. The temporally averaged total energy flux increase from all of the lakes combined is $2.86 \times 10^{13} \mathrm{~W}$ between CTRL and NOICE and $2.61 \times 10^{13} \mathrm{~W}$ between NOICE and LST3K; a difference of $8 \%$. Note that the increase in surface heat flux would have been greater (less) than in our simulations if the control ice coverage had been larger (smaller). Cordeira and Laird (2008) observed a 
reduction of $85 \%$ and $95 \%$ of total energy flux off of Lake Erie from open-water to ice-covered conditions in two separate LES cases.

Next, we examine how changes in sensible and latent heat fluxes affect the stability and height of the planetary boundary layer. We focus our analysis on Lake Erie, which exhibits large fractional ice coverage in CTRL and is thus strongly influenced by the removal of ice. Figure 8 depicts the modeled vertical temperature and dewpoint temperature profile at 1200 UTC 16 January averaged over a $6 \mathrm{~km} \times 6 \mathrm{~km}$ grid in central Lake Erie as compared with another $6 \mathrm{~km} \times 6 \mathrm{~km}$ region over southern Michigan ( $\times \mathrm{s}$ in Fig. 1). A strong LES band was located along the southeastern shore of Lake Erie at this time (Fig. 3f).

Increases in open-water area and in lake surface temperature result in nearly equivalent precipitable water vapor (PWV) increases between CTRL and NOICE (Figs. 8d,e), and between NOICE and LST3K (Figs. 8e,f) over Lake Erie. In contrast, while there is a monotonic increase in PW between CTRL, NOICE, and LST3K over land (Figs. 8a-c), the largest increase occurs for the transition between NOICE and LST3K (Figs. 8b,c, respectively). The increase in PWV from CTRL to NOICE in both locations is due to removal of lake ice and increase in open-water fetch; because there is relatively smaller initial ice cover on Lake Michigan upstream (Fig. 2c) of the inland point, the increase in PWV is smaller than it is over Lake Erie. In contrast, the increase in PWV produced by increases in surface heat fluxes associated with surface warming is comparable for the overland and overlake points.

In the CTRL case (Fig. 8d), convective available potential energy (CAPE) calculated from a surface based parcel is minimal at $9 \mathrm{~J} \mathrm{~kg}^{-1}$. The NOICE and LST3K cases exhibit greater buoyant instability with CAPE values of 63 and $93 \mathrm{~J} \mathrm{~kg}^{-1}$, respectively (Figs. 8e,f). While values of CAPE are relatively low in all simulations, observations have shown that large positive CAPE values are not necessary for LES formation (Schultz 1999). The near-zero CAPE values in CTRL are the result of a near-isothermal stable layer located approximately $500 \mathrm{~m}$ above the surface (Fig. 8d). Examination of the time evolution of the upstream low-level temperature distribution reveals this layer to be created over land and partially frozen lakes through overnight radiative cooling. The result is a strong $\left[4 \mathrm{~K}(500 \mathrm{~m})^{-1}\right]$ low-level temperature inversion (Fig. 8a). In CTRL, the Lake Erie sounding is located just downstream of the ice edge (Fig. 1), and in this case there has not been sufficient sensible heat transfer from the lake to the atmosphere to entirely remove the stable layer. The temperature inversion upstream of Lake Erie in NOICE and LST3K (Figs. 8b,c) is of similar magnitude and depth to CTRL, but in these cases surface sensible heat flux from the longer open water fetch over the ice-free western end of Lake Erie has sufficient mixing to eliminate the inversion. While the properties of the low-level temperature inversion are similar in all three cases, the depth and water vapor content of the boundary layer increase in both NOICE and LST3K. The fact that qualitatively similar changes are observed both over and upstream of Lake Erie indicates the importance of the upstream lakes in modifying the thermodynamic environment. The influence of the upwind lakes on downwind LES has been observed in previous studies (Rodriguez et al. 2007; Sousounis and Mann 2000). In this case, warming over the upwind lakes helps to "prime" the atmosphere by warming the boundary layer and reducing the stability of the lower troposphere. This in turn leads to greater instability over the lake as the low-level inversion mixes out, giving the potential for deeper updrafts and more intense precipitation.

\section{c. Precipitation structure}

The deeper and more well-mixed boundary layers exhibited by NOICE and LST3K allow for consequent increases in column-integrated water vapor, larger buoyant instability, and the possibility of deeper vertical circulations, and it is likely this that contributes to the observed increases in precipitation amount and areal extent (Figs. 4-6). We now examine the impact of lake ice changes on the cloud-scale structure of the LES snowbands, focusing our analysis on Lakes Erie and Ontario. Lake Erie is selected because it has the largest fractional ice cover of the five major Great Lakes in the CTRL case and exhibits marked changes in precipitation morphology over the lifetime of the case, while Lake Ontario exhibits a well-defined midlake snowband. We utilize the $1-\mathrm{km}$ grid-spacing nest in this analysis as it facilitates a more realistic representation of local-scale topography and precipitation features. Onehour accumulated liquid equivalent precipitation is used to depict the structure of the lake-effect snow features around Lakes Erie and Ontario (Fig. 9). As the synopticscale flow evolves, the air temperature and overlake fetch change, leading to distinctly different precipitation regimes. We select three representative times that each illustrate different precipitation morphology.

At 1200 UTC 15 January, lower-tropospheric winds over the Great Lakes were primarily northerly (Fig. 2a), resulting in relatively short fetch over Lake Erie and the development of a shoreline snowband along the southern shore (Figs. 9a-c). Though ice cover limited the horizontal extent of this band in CTRL (Fig. 9a), 
Southern Michigan

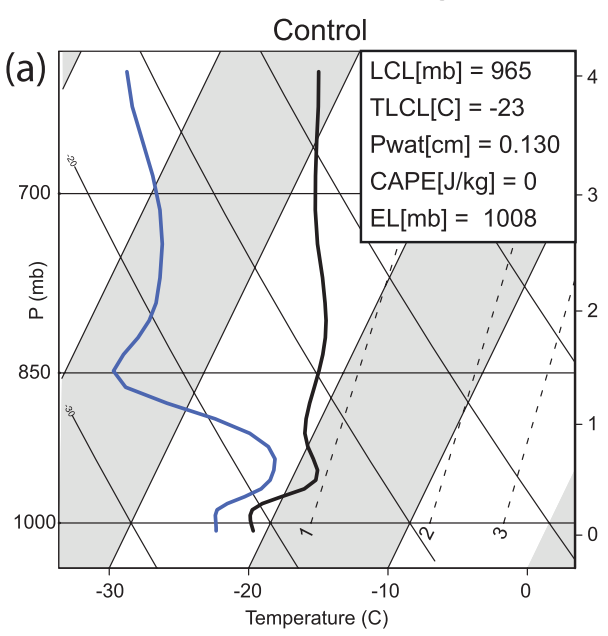

NOICE

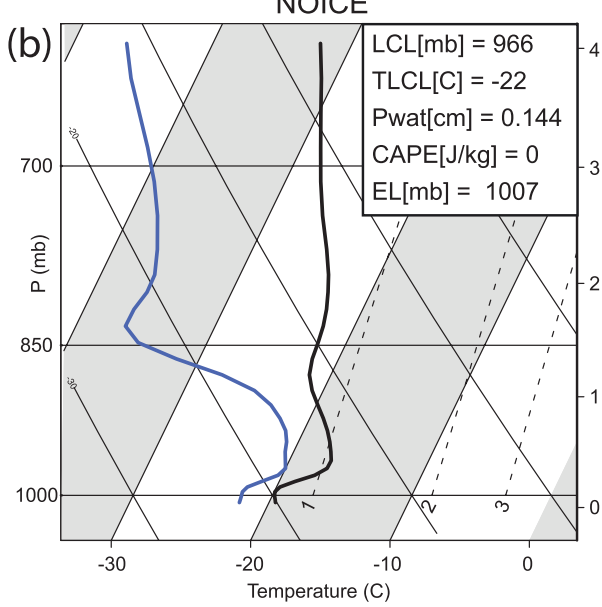

LST3K

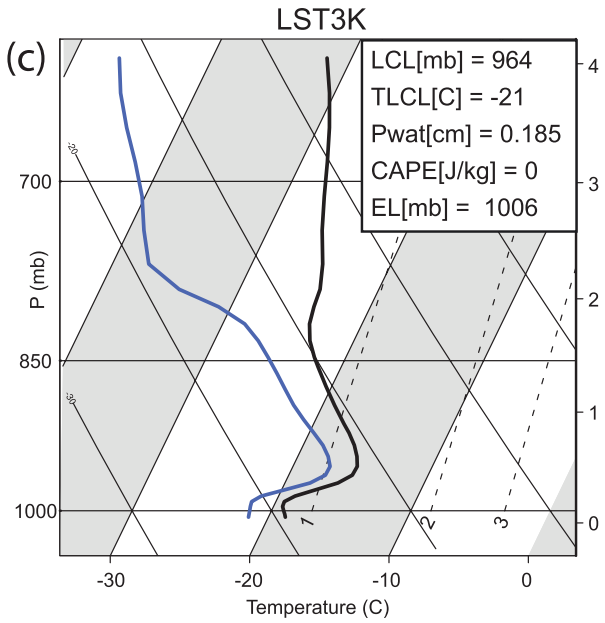

Lake Erie
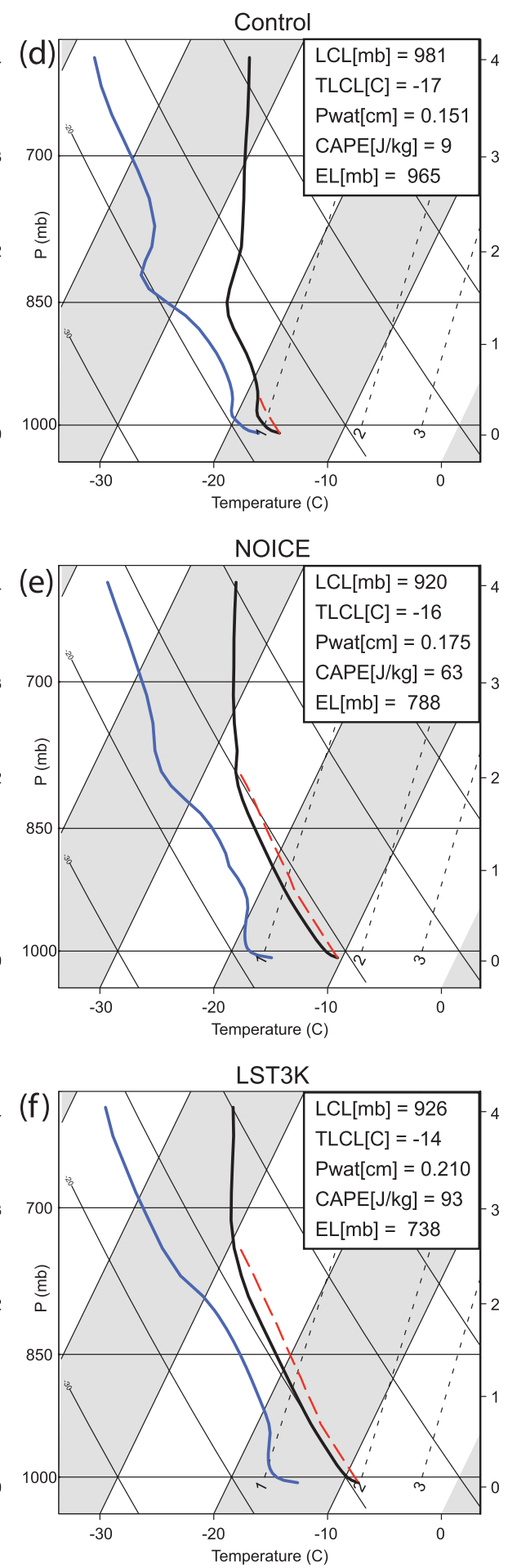

FIG. 8. Skew $T-\log p$ plots of atmospheric soundings for (a),(d) CTRL case; (b),(e) NOICE case; and (c),(f) LST3K case at 1200 UTC 16 Jan, and averaged over a $6 \mathrm{~km} \times 6 \mathrm{~km}$ grid located over (a)-(c) southern Michigan and (d)-(f) Lake Erie. The location of each $6 \mathrm{~km} \times 6 \mathrm{~km}$ grid is shown in the $\times \mathrm{s}$ in Fig. 1. In each figure, the black line represents the temperature, the blue line represents the dewpoint temperature, and the red dashed line represents the temperature of a parcel lifted from the surface. 


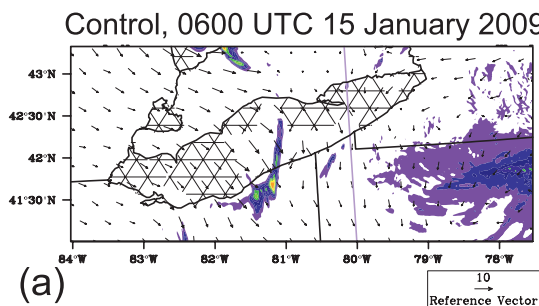

(a)

Control, 2100 UTC 15 January 2009

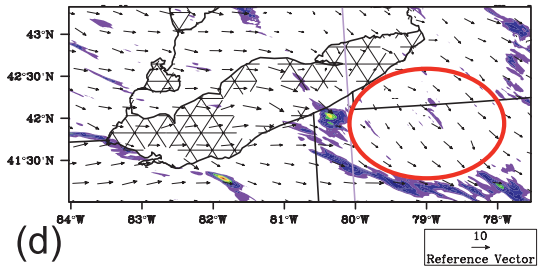

Control, 1200 UTC 16 January 2009

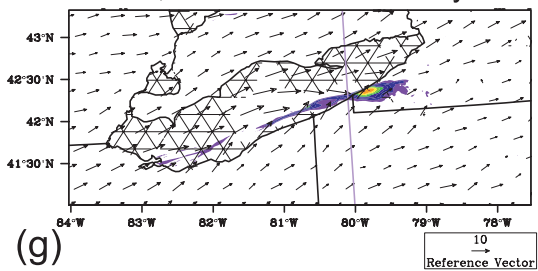

(g)

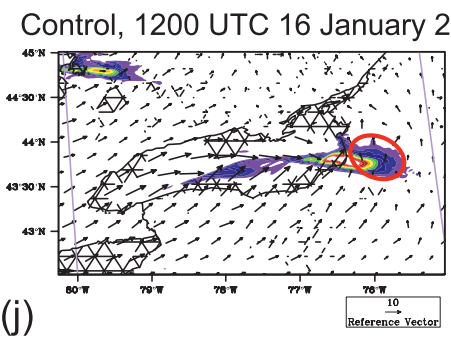

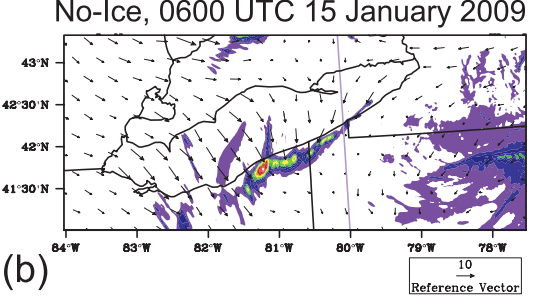

No-Ice, 2100 UTC 15 January 2009

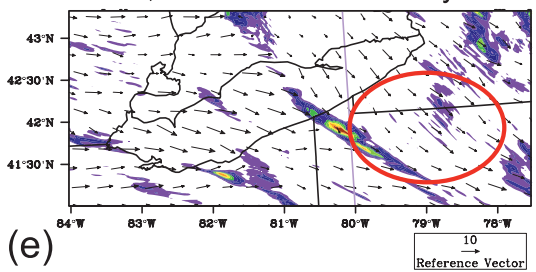

No-Ice, 1200 UTC 16 January 2009

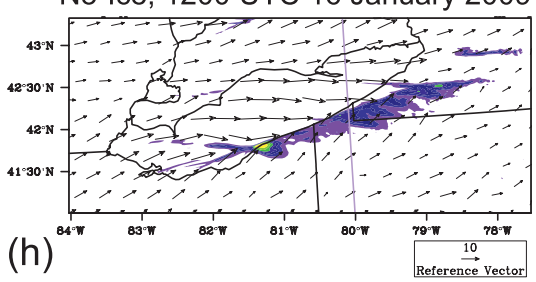

No-Ice, 1200 UTC 16 January 2009

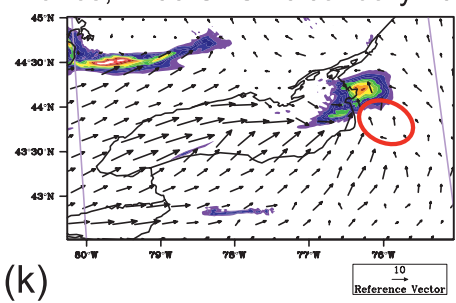

LST +3K, 0600 UTC 15 January 2009

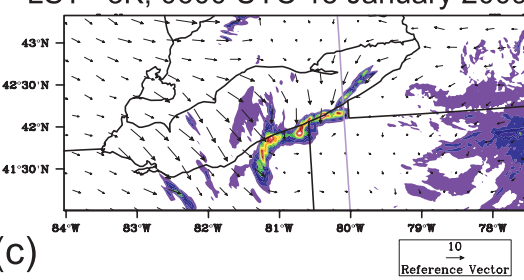

LST +3K, 2100 UTC 15 January 2009

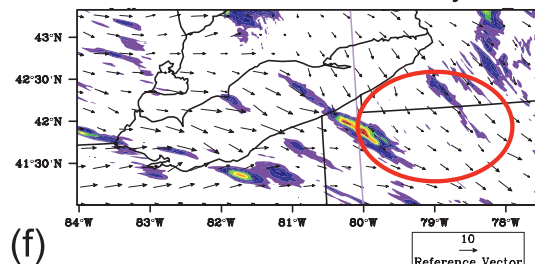

LST +3K, 1200 UTC 16 January 2009

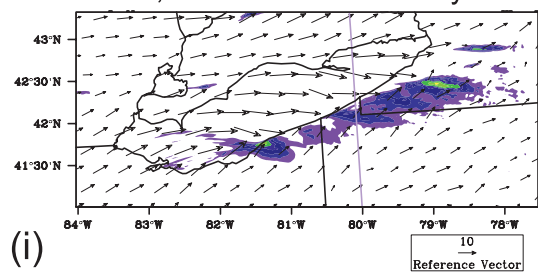

LST +3K, 1200 UTC 16 January 2009

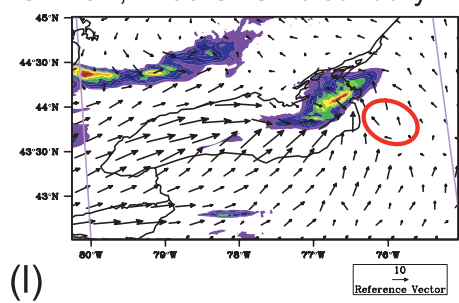

$\begin{array}{llllllllllllll}0.25 & 0.5 & 0.75 & 1 & 1.25 & 1.5 & 1.75 & 2 & 2.25 & 2.5 & 2.75 & 3\end{array}$

FIG. 9. Simulated 1-h accumulated liquid equivalent precipitation ( $\mathrm{mm}$, color filled contours) and 10-m wind vectors ( $\left.\mathrm{m} \mathrm{s}^{-1}\right)$ for the (a),(d), (g),(j) control; (b),(e),(h),(k) no-ice; and (c),(f),(i),(l) +3-K LST simulations at three different times [(a)-(c) 0600 UTC 15 Jan, (d)-(f) 2100 UTC 15 Jan, and (g)-(1) 1200 UTC 16 Jan 2009]. The cross-hatched shading in the first column depicts the extent of ice cover in the control case. Note the first three rows depict Lake Erie, while the last row corresponds to Lake Ontario. Red circles in (d)-(f) and (j)-(l) depict the location of the Allegheny and Tug Hill Plateaus, respectively.

increases in wind speed with transition from ice to water serve to enhance a midlake convergence zone and the associated precipitation over the lake. Removal of the lake ice and increase in LST (Figs. 9b,c) result in the expansion of LES along the southern Lake Erie shoreline, as well as a general increase in LES magnitude. In a manner similar to the influence of the ice edge geometry in CTRL, the concave northern shore (to the south) produces midlake convergence in the ice-free cases; however, the convergence is weaker and the north-south-oriented midlake band is diminished in intensity. Precipitation in LST3K develops farther upwind of the lake shore than in NOICE, perhaps due to more rapid boundary layer destabilization caused by greater surface heat fluxes.

By 2100 UTC 15 January, the synoptic-scale flow was directed from northwest to southeast over the Great Lakes (Figs. 2a,b), leading to a change in the precipitation morphology from relatively widespread with embedded shoreline bands (Figs. 9a-c) to widely separated flow-parallel bands (Figs. 9d-f). This transition happens because of changes in fetch over the lake, and is broadly consistent with Laird et al.'s (2003a) idealized simulations, which showed a morphological transition from widespread coverage toward shoreline bands as the ambient flow direction changed from across to along 


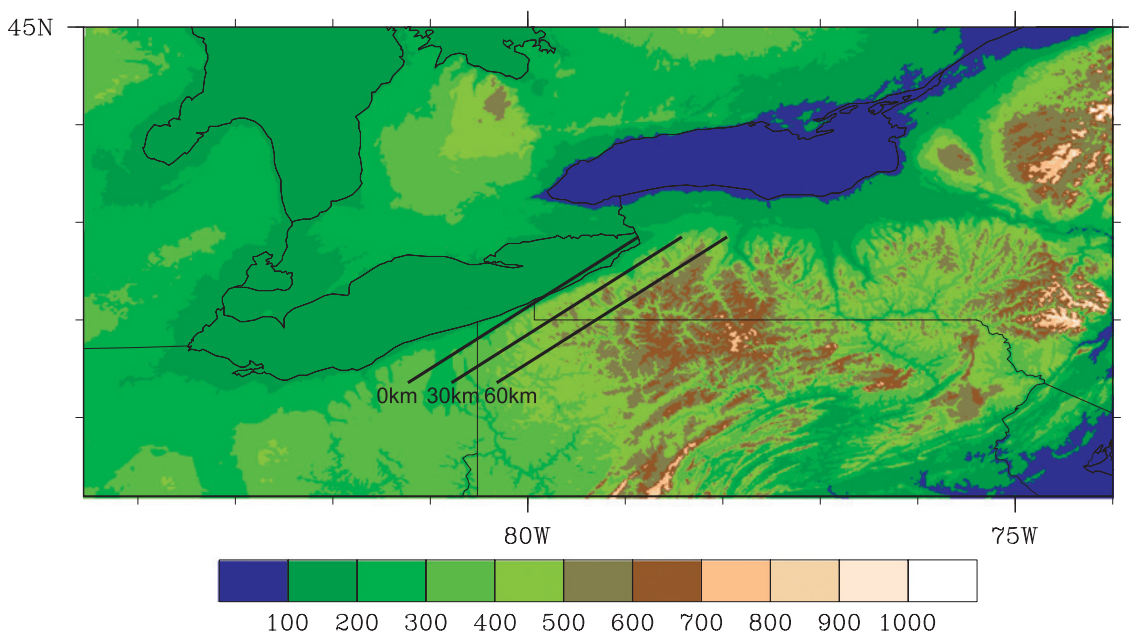

FIG. 10. Terrain height above sea level (m, color filled contours). The position of each of the transects in Figs. 11-13 are indicated in the solid black lines.

the major (longer) lake axis. Close examination of the flow pattern to the south and east of Lake Erie reveals a complex interaction with the western side of the Allegheny Plateau (circled in red in Figs. 9d-f; see also the terrain height map in Fig. 10). Divergent flow around the Allegheny Plateau leads to local convergence on the southwest side in all cases, and to enhancement of the upstream midlake band in NOICE and LST3K (Figs. 9e,f). Precipitation is likely limited over the Allegheny Plateau at this time because the overlake fetch is short.

At 1200 UTC 16 January, winds were oriented from west to east across Lake Erie and most of the rest of the Great Lakes region (Fig. 2c). In the CTRL case (Fig. 9g), extensive ice cover inhibits the development of precipitation, with snowfall restricted to a single band downstream of the largest patch of open water. When all ice is removed from the lake (Fig. 9h), leeside snowfall becomes more widespread. Increasing the lake temperature (Fig. 9i) results in expansion of LES downstream, but little change to the precipitation amount. Note that the upstream edge of the region of precipitation does not change between NOICE and LST3K, nor do the positions of the downstream snowbands. This indicates that, while the amount of precipitation is dictated by the surface properties and air temperature, the location is governed by the local geography.

The final row of Fig. 9 depicts a midlake band over Lake Ontario at 1200 UTC 16 January. In the CTRL case (Fig. 9j), 10-m wind vectors show low-level convergence occurring near the center of the lake, creating the midlake band. In the NOICE case (Fig. 9k), increases in overlake fluxes lead to greater boundary layer destabilization, an increase in updraft velocity, and consequent increases in midlake convergence. Removal of ice from the northern portion of the lake causes the band and convergence zone to shift to the north. Preferential movement of the band to the north is likely due to the removal of the ice cover in the north-central portion of the lake. The resulting decrease in roughness length from ice cover to open water allows for the development of a more southerly low-level flow. Decreases in precipitation intensity over the eastern end of Lake Ontario are due to changes in the interaction between the snowband and topography. In the control case, the flow and band impinge directly on the Tug Hill Plateau (indicated in the red circle in Figs. 9j-1; see also Fig. 10), an elevated region just east of the eastern end of Lake Ontario that rises to a height of just over $600 \mathrm{~m}$ above sea level. The northward shift in the midlake band induced by removal of ice causes the band to be positioned to the north of the Tug Hill Plateau in a region with less orographic enhancement of precipitation. Snowfall in the LST3K case (Fig. 91) develops farther upstream of the lake shore, likely due to more rapid destabilization of the boundary layer over the warmer lake waters.

Examination of hourly precipitation suggests that changes in lake surface properties produce local increases in magnitude and expansion in the areal extent of precipitation. It is clear, however, that these changes also interact strongly with the local topography and lake-shore geometry. To further explore these interactions, and to obtain a more detailed process level perspective on the boundary layer and cloud vertical structure, we examine cross sections at 1200 UTC 16 January located at distances of approximately 0,30 , and $60 \mathrm{~km}$ from the southeastern Lake Erie shoreline (Fig. 10). The orientation is chosen to strike a balance between cross sections that are parallel to the shoreline 

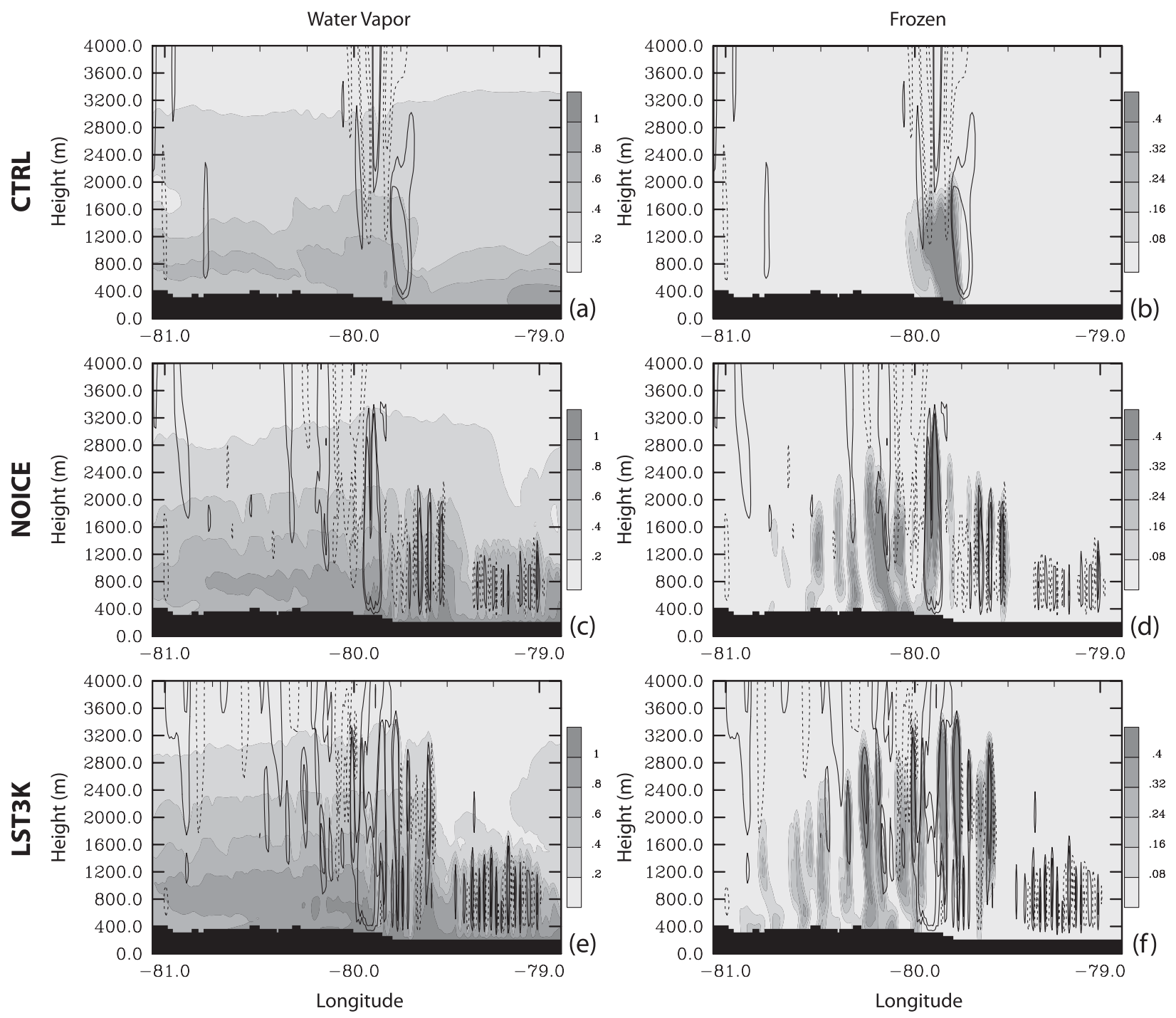

FIG. 11. Vertical cross sections of water vapor and frozen (sum of snow, ice, and graupel) mass mixing ratios ( $\mathrm{g} \mathrm{kg}^{-1}$, grayscale filled contours) overlaid with contours of vertical velocity $\left(\mathrm{m} \mathrm{s}^{-1}\right.$, every $0.5 \mathrm{~m} \mathrm{~s}^{-1}$ between -1.0 and $1.0 \mathrm{~m} \mathrm{~s}^{-1}$, unfilled black contours; negative values are dashed) for 1200 UTC 16 Jan 2009 at the 0-km transect plotted in Fig. 10. Note that the total liquid mass (cloud and rain) was negligible at this time.

and also as close to perpendicular to the flow-parallel precipitation features as possible.

The cross section nearest the lake shore includes land to the southwest and water to the northeast, with the transition between land and lake located at approximately $79.8^{\circ} \mathrm{W}$ longitude. Examination of the vertical distribution of water vapor (Figs. 11a,c,e) indicates the top of the boundary layer (as determined by the mean height of the tops of shallow convective plumes) is approximately $600-800 \mathrm{~m}$ higher over land versus over the lake. The height of the $0.2 \mathrm{~g} \mathrm{~kg}^{-1}$ water vapor mixing ratio contour is relatively constant over the land, and there is a monotonic increase in near-surface water vapor content in NOICE and LST3K. Over the lake, the $0.2 \mathrm{~g} \mathrm{~kg}^{-1}$ contour lowers with removal of ice and increase in LST (Figs. 11c,e). This is possibly due to 1) more vigorous mixing between shallow convection in the boundary layer and the free troposphere above, and 2) localized surface level divergence (and consequent subsidence above it) along the upwind shore as the reduction in surface friction causes low-level air to accelerate as it flows from land over the open lake water. No such increase is exhibited with transition from land to ice in CTRL, largely because the surface roughness of ice in the model is set equivalent to that of dry frozen soil. CTRL exhibits a single snowband, located at the 

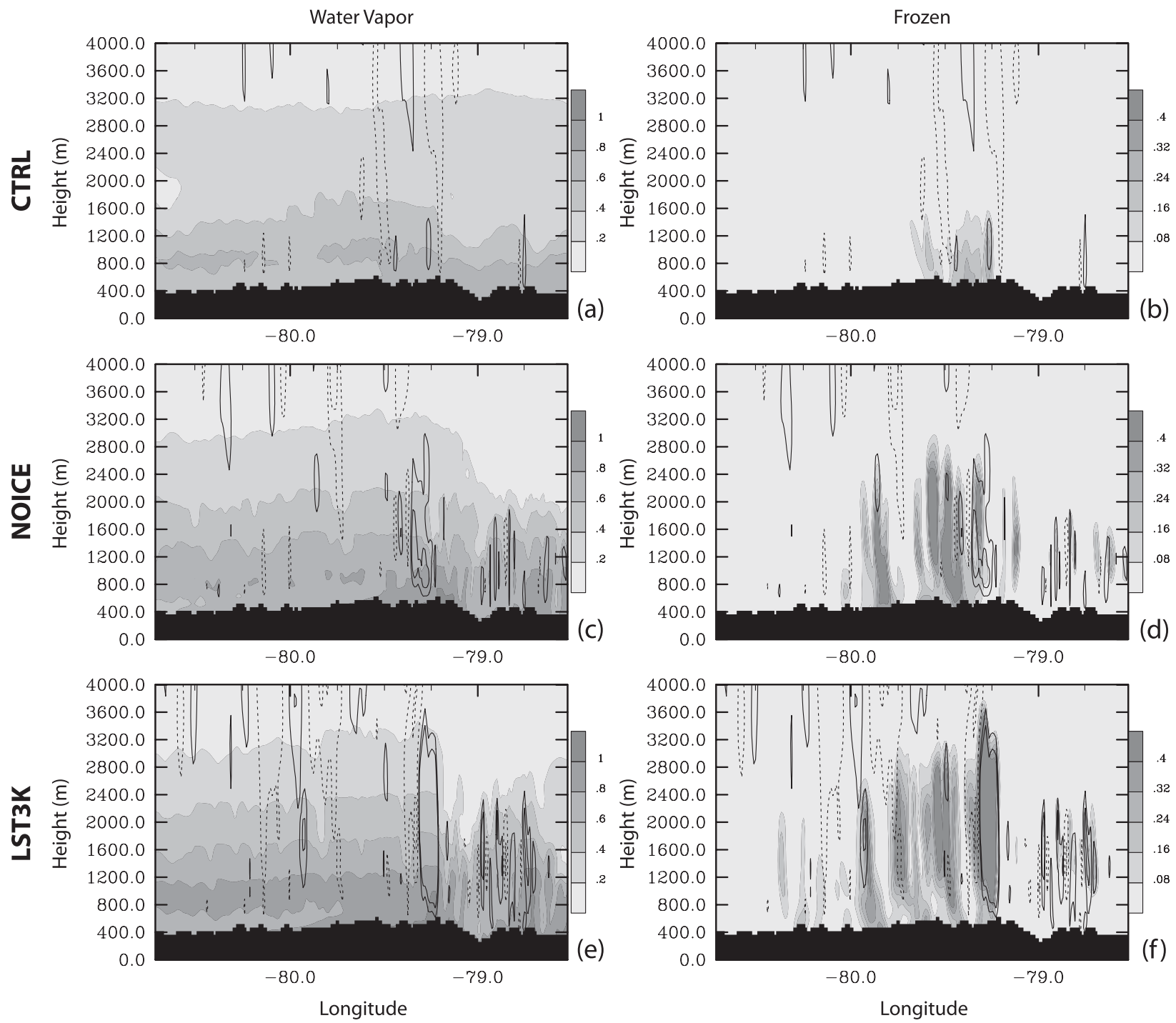

FIG. 12. As in Fig. 11, but at a location $30 \mathrm{~km}$ downwind of the southern Lake Erie shoreline.

boundary between land and lake (Figs. 11a,b); this is the band associated with midlake convergence noted above in Fig. 9a. The presence of ice on the lake reduces the available water vapor, and there is no cloud over the lake or land to the east or west of this band. Removal of ice (Figs. 11c,d) leads to the appearance of shallow narrow updrafts over the lake with broader and deeper regions of snowfall over the land. Clouds over both the lake and land increase in depth with an increase in LST (Fig. 11f), though increases are larger over land ( $\sim 400$ $600 \mathrm{~m})$ than over the lake $(\sim 200 \mathrm{~m})$. Mean vertical velocity in updrafts changes little across the three cases, though detailed examination of the simulated vertical velocity field indicates the maximum updraft speed increases with transition from CTRL to NOICE and from NOICE to LST3K. Comparison of ice mass mixing ratio in each of the three cases reveals little consistency in the location of clouds over water or land in CTRL, NOICE, and LST3K, with the exception of the land-lake boundary, which is a locus of snowfall in each case.

At $30 \mathrm{~km}$ downwind of the lake-shore transect (Fig. 12), the single snowband in the CTRL case is shallow and contains approximately $0.16 \mathrm{~g} \mathrm{~kg}^{-1}$ less mass mixing ratio compared to locations along the lake shore. Upward vertical velocity and boundary layer water vapor content in all three cases is much smaller than in the alongshore transect, but there is little reduction in snow mass content in NOICE and LST3K. In contrast to the along-lake transect, cloud features appear in approximately the same locations in NOICE and LST3K. Close examination of the cross-section location relative to the terrain height (Fig. 10) indicates several north-south-oriented spurs of 

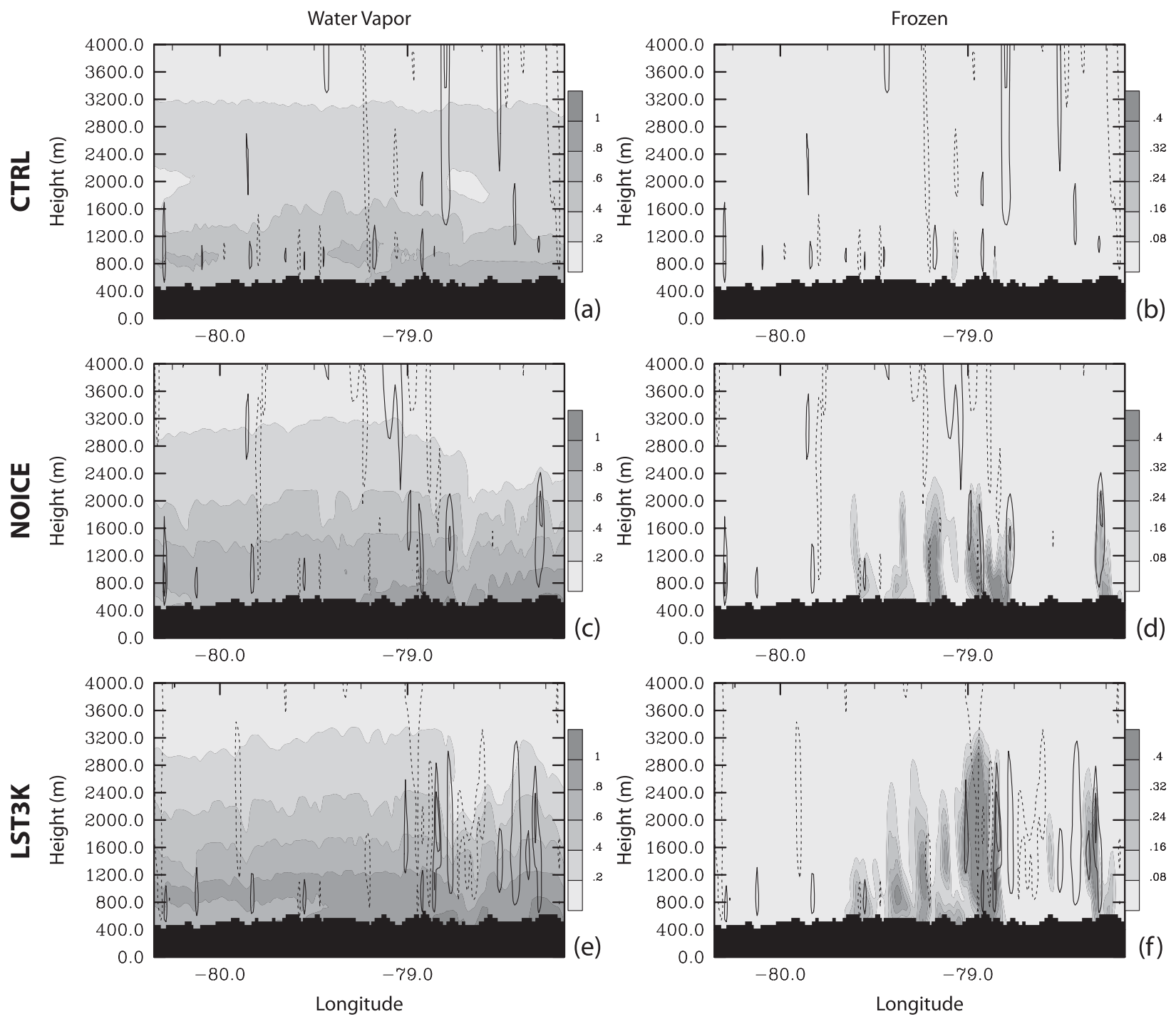

FIG. 13. As in Fig. 11, but at a location $60 \mathrm{~km}$ downwind of the southern Lake Erie shoreline.

the Allegheny Plateau extend into the cross section. While the influence of topography certainly also extends downstream, it appears that flow impinging on these spurs may serve to concentrate precipitation via local orographic enhancement. Locations to the north of the Allegheny Plateau (east of $79^{\circ} \mathrm{W}$ longitude) experience less orographic enhancement, and the boundary layer remains relatively shallow and precipitation concentrated in narrower bands. In contrast, updrafts over the Allegheny Plateau are approximately 2 times deeper and clouds are significantly wider.

At locations $60 \mathrm{~km}$ downwind of the Lake Erie shoreline (Fig. 13), clouds are nearly nonexistent in CTRL. Clouds persist in NOICE and LST3K, though cloud-top heights are 400-1000 m lower in comparison to locations nearer the lake shore. The cross section is located almost entirely over the Allegheny Plateau, and many of the cloud features are associated with gradients in topography. This is particularly true of the elevated regions around $79.0^{\circ}$ and $78.2^{\circ} \mathrm{W}$ longitude. While changes in overlake fetch can produce spatially consistent patterns in downstream snowband location and intensity, the fetch over Lake Erie upstream of each of the cross sections changes little in the west-east direction. Examination of the terrain height map (Fig. 10) indicates the topographic gradients seen in Fig. 13 extend both upstream and downsteam of the cross section, and it is reasonable to conclude that the snowband location is being influenced by flow along a local topographic feature.

The cross-sectional analysis suggests that the bulk surface fluxes determine the boundary layer water vapor 
content and by extension the amount of cloud mass that can be produced in each LES band. However, it appears that two sets of processes serve to generate snowfall at and downstream of the lake shore. Frictional convergence at the land-lake boundary generates a significant amount of cloud mass, and greater amounts are found in cases with larger surface sensible and latent heat flux. Cloud mass generated at and near the lake shore is advected downstream, and advection of larger cloud amounts in the NOICE and LST3K cases leads to expansion in the LES region. However, in addition to the regional-scale bulk thermodynamic response, smallscale horizontal gradients in topography serve to focus the snowbands and locally enhance snowfall amounts.

\section{Summary and conclusions}

In this study, we have used the Weather Research and Forecasting Model to examine how changes to lake surface properties affect snowfall distribution and amount for a case of lake-effect snowfall in the Great Lakes region. Four cases were simulated: 1) a control case in which lakes were initialized with NARR-analyzed ice cover, 2) an all-ice case in which lakes were completely ice covered, 3 ) a no-ice case in which lakes were completely ice free, and 4) an ice-free case with $3-\mathrm{K}$ increase in LST. This case study approach to understanding lake-land-atmosphere interactions is advantageous in that the WRF configuration we have chosen is capable of simulating the meso- $\gamma$-scale features associated with the development of intense lake-effect snowfall. Our simulations have the appropriate resolution to capture the complex geography in the Great Lakes region.

The major conclusions of our study include the following:

1) As has been reported in previous studies, the location and extent of lake ice places a severe constraint on the location and intensity of LES. Our simulations indicate ice cover can, via changes in surface roughness around the ice edge, serve to focus and enhance precipitation in some cases.

2) With removal of lake ice and warming of the surface, lakes with short overwater fetch exhibit increases in the downstream extent of LES. By contrast, once ice is removed, lakes with relatively large overwater fetch show little additional downwind propagation of LES with increases in lake temperature.

3) Consistent with findings from prior LES research, fetch, wind speed, and wind direction determine the precipitation morphology. We find that the pattern of low-level flow, and the interaction between wind and the lake shore geography and downstream topography, exerts a strong influence on the location of precipitation at the surface. For shoreline bands and widespread coverage, topography and lake shore geography largely determine the spatial pattern of precipitation. Increases in LST serve primarily to increase the downwind extent of the heaviest precipitation. In contrast, the position of midlake bands (e.g., over Lake Ontario) is found to be sensitive to increases in LST, largely through the influence of lake surface fluxes on the strength of convection and midlake convergence.

4) Upslope enhancement of precipitation due to elevated topography downwind of the lakes is critical in determining the response of precipitation to changes in lake surface properties. In regions with complex downstream terrain, LES is generated both via lake shore convergence, and by local orographic enhancement.

5) Finally, examination of cross sections through flow parallel bands (Figs. 11-13) indicates that an increase in LST does not significantly change the mean snowband updraft strength, but does lead to a narrowing and deepening of each band consistent with increases in boundary layer depth and buoyant instability. This suggests that the extended downwind propagation observed in the accumulated precipitation is due to a complex interaction between destabilization of air over the warmer waters and the location of regions of convergence and complex topography created along the shore.

These results have the following implications for the study of future climate in the Great Lakes region:

1) With reductions in lake ice, a greater area along the downwind shores of the Great Lakes may be exposed to increases in intense LES events.

2) With increases in LST, intensity of LES events increases along with the propagation downwind of LES.

3) The formation of LES is strongly coupled to the open-water characteristics, as well as shoreline geography and topography. While LES events may become more intense, the spatial distribution of precipitation is strongly influenced by the location of topographic features, suggesting models that do not realistically represent the interaction between precipitation and orography may have difficulty capturing the local-scale distribution of snowfall.

Sensitivity of the LES distribution and intensity to lake surface conditions in our simulations is consistent with detailed observation-based studies of the ice coverLES relationship (e.g., Cordeira and Laird 2008). 
Though applicability of our conclusions to future climate states is limited by the examination of a single LES event, the analysis presented here exhibits a wide range of observed LES morphology including widespread snow, shoreline bands, and midlake bands. The suite of simulations performed illustrates the various mechanisms that trigger LES in the Great Lakes region, and lends insight into a broader spectrum of cases in which LES is generated by cold-air outbreaks.

Ultimately, the long-term effects of changes to Great Lakes surface properties must be studied using simulations that span time scales of decades or longer, and can accurately capture the interannual variability of lake ice coverage (e.g., Notaro et al. 2013). The fact that ice cover concentration critically controls the amount and location of lake-effect precipitation downwind of each of the Great Lakes has important implications for the design of decadal experiments. Specifically, accurate and realistic prediction of the timing of lake ice onset and melt, as well as the extent of cold season ice coverage and thickness, are critical for determining the timing and amount of lake-effect (and by extension lake-enhanced) precipitation in future climate states. Finescale numerical experiments can be used to anchor coarser-resolution simulations and may aid in the production of more accurate predictions of Great Lakes climate.

Acknowledgments. This material is based upon work supported by the National Science Foundation under Grant 1039043. Initialization data was obtained from the National Climatic Data Center (NCDC) and radar observations were provided by University Corporation for Atmospheric Research (UCAR) and the College of DuPage. Ice observations were obtained from the $\mathrm{Na}$ tional Ice Center. WRF simulations were performed on the University of Michigan Center for Advanced Computing $(\mathrm{CaC})$ flux cluster and we appreciate the support of Brock Palen and the $\mathrm{CaC}$ staff. The comments of three anonymous reviewers led to improvements in the focus and quality of the manuscript.

\section{REFERENCES}

Assel, R. A., 2005: Classification of annual Great Lakes ice cycles: Winters of 1973-2002. J. Climate, 18, 4895-4905.

—, K. Cronk, and D. Norton, 2003: Recent trends in Laurentian Great Lakes ice cover. Climatic Change, 57, 185-204.

Ballentine, R. J., A. J. Stamm, E. F. Chermack, G. P. Byrd, and D. Schleede, 1998: Mescoscale model simulation of the 4-5 January 1995 lake-effect snowstorm. Wea. Forecasting, 13, 893-920.

Burnett, A. W., M. E. Kirby, H. T. Mullins, and W. P. Patterson, 2003: Increasing Great Lake-effect snowfall during the twentieth century: A regional response to global warming? J. Climate, 16, 3535-3543.

Cordeira, J. M., and N. F. Laird, 2008: The influence of ice cover on two lake-effect snow events over Lake Erie. Mon. Wea. Rev., 136, 2747-2763.

Durran, D. R., 2000: Comments on "The differentiation between grid spacing and resolution and their application to numerical modeling." Bull. Amer. Meteor. Soc., 81, 2478-2479.

Eichenlaub, V. L., 1970: Lake effect snowfall to the lee of the Great Lakes: Its role in Michigan. Bull. Amer. Meteor. Soc., 51, 403-412. , 1979: Weather and Climate of the Great Lakes Region. University of Notre Dame Press, 335 pp.

Gerbush, M. R., D. A. R. Kristovich, and N. F. Laird, 2008: Mesoscale boundary layer and heat flux variations over pack icecovered Lake Erie. J. Appl. Meteor. Climatol., 47, 668-683.

Grasso, L. D., 2000: The differentiation between grid spacing and resolution and their application to numerical modeling. Bull. Amer. Meteor. Soc., 81, 579-580.

Holroyd, E. W., 1971: Lake-effect cloud bands as seen from weather satellites. J. Atmos. Sci., 28, 1165-1170.

Kelly, R. D., 1986: Mesoscale frequencies and seasonal snowfalls for different types of Lake Michigan snow storms. J. Climate Appl. Meteor., 25, 308-312.

Kristovich, D. A. R., and N. F. Laird, 1998: Observations of widespread lake-effect cloudiness: Influences of LST and upwind conditions. Wea. Forecasting, 13, 811-821.

,-- M. R. Hjelmfelt, R. G. Derickson, and K. A. Cooper, 1999: Transitions in boundary layer meso- $\gamma$ convective structures: An observational case study. Mon. Wea. Rev., 127, 28952909.

, — , and - 2003: Convection evolution across Lake Michigan during a widespread lake-effect snow event. Mon. Wea. Rev., 131, 643-655.

Kunkel, K. E., N. E. Westcott, and D. A. R. Kristovich, 2002: Assessment of potential effects of climate change on heavy lakeeffect snowstorms near Lake Erie. J. Great Lakes Res., 28, 521-536.

— L. Ensor, M. Palecki, D. Easterling, D. Robinson, K. G. Hubbard, and K. Redmond, 2009: A new look at lake-effect snowfall trends in the Laurentian Great Lakes using a temporally homogeneous data set. J. Great Lakes Res., 35, 23 29

Laird, N. F., 1999: Observation of coexisting mesoscale lake-effect vortices over the western Great Lakes. Mon. Wea. Rev., 127, 1137-1141.

— with idealized model results for a method to resolve winter lake-effect mesoscale morphology. Mon. Wea. Rev., 132, 1093-1103.

$\longrightarrow,-$, and J. E. Walsh, 2003a: Idealized model simulations examining the mesoscale structure of winter lake-effect circulations. Mon. Wea. Rev., 131, 206-221.

— J. E. Walsh, and D. A. R. Kristovich, 2003b: Model simulations examining the relationship of lake-effect morphology to lake shape, wind direction, and wind speed. Mon. Wea. Rev., 131, 2102-2111.

Liu, A. Q., G. W. K. Moore, K. Tsuboki, and I. A. Renfrew, 2004: A high-resolution simulation of convective roll clouds during a cold-air outbreak. Geophys. Res. Lett., 31, L03101, doi:10.1029/ 2003 GL018530.

,,---1, and,- 2006 : The effect of the sea-ice zone on the development of boundary-layer roll clouds during cold air outbreaks. Bound.-Layer Meteor., 118, 557-581. 
Niziol, T. A., 1987: Operational forecasting of lake effect snowfall in western and central New York. Wea. Forecasting, 2, 310 321.

— W. R. Snyder, and J. S. Waldstreicher, 1995: Winter weather forecasting throughout the eastern United States. Part IV: Lake effect snow. Wea. Forecasting, 10, 61-77.

Notaro, M., A. Zarrin, S. Vavrus, and V. Bennington, 2013: Simulation of heavy lake-effect snowstorms across the Great Lakes basin by RegCM4: Synoptic climatology and variability. Mon. Wea. Rev., in press.

Rodriguez, Y., D. A. R. Kristovich, and M. R. Hjelmfelt, 2007: Lake-to-lake cloud bands: Frequencies and locations. Mon. Wea. Rev., 135, 4202-4213.

Schoenberger, L. M., 1986: Mesoscale features of the Michigan land breeze using PAM II temperature data. Wea. Forecasting, 1, 127-135.

Schultz, D. M., 1999: Lake-effect snowstorms in northern Utah and western New York with and without lightning. Wea. Forecasting, 14, 1023-1031.

Scott, R. W., and F. A. Huff, 1996: Impacts of Great Lakes on regional climate conditions. J. Great Lakes Res., 22, 845 863.

Shi, J. J., and Coauthors, 2010: WRF simulations of the 20-22 January 2007 snow events over eastern Canada: Comparison with in situ and satellite observations. J. Appl. Meteor. Climatol., 49, 2246-2266.
Sousounis, P. J., and G. E. Mann, 2000: Lake-aggregate mesoscale disturbances. Part V: Impacts on lake-effect precipitation. Mon. Wea. Rev., 128, 728-745.

Trumpickas, J., B. J. Shuter, and C. K. Minns, 2009: Forecasting impacts of climate change on Great Lakes surface water temperatures. J. Great Lakes Res., 35, 454-463.

Vavrus, S., J. E. Walsh, W. L. Chapman, and D. Portis, 2006: The behavior of extreme cold air outbreaks under greenhouse warming. Int. J. Climatol., 26, 1133-1147.

_- M. Notaro, and A. Zarrin, 2013: The role of ice cover in heavy lake-effect snowstorms over the Great Lakes basin as simulated by RegCM4. Mon. Wea. Rev., 141, 148-165.

Walsh, J. E., A. S. Phillips, D. H. Portis, and W. L. Chapman, 2001: Extreme cold outbreaks in the United States and Europe, 1948-99. J. Climate, 14, 2642-2658.

Wang, J., X. Bai, G. Leshkevich, M. Colton, A. Clites, and B. Lofgren, 2010: Severe ice cover on great lakes during winter 2008-2009. Eos, Trans. Amer. Geophys. Union, 91(5), 41, doi:10.1029/2010EO050001.

Wiggin, B. L., 1950: Great snows of the Great Lakes. Weatherwise, 3, 123-126.

Zulauf, M. A., and S. K. Krueger, 2003: Two-dimensional cloudresolving modeling of the atmospheric effects of Arctic leads based upon midwinter conditions at the Surface Heat Budget of the Arctic Ocean ice camp. J. Geophys. Res., 108, 4312, doi:10.1029/2002JD002643. 